\title{
The Traveling-Wave Tube in the History of Telecommunication
}

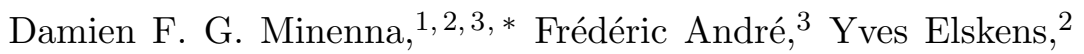 \\ Jean-François Auboin, ${ }^{3}$ Fabrice Doveil, ${ }^{2}$ Jérôme Puech, ${ }^{1}$ and Élise Duverdier \\ ${ }^{1}$ Centre National d'Études Spatiales, 31401 Toulouse cedex 9, France \\ ${ }^{2}$ Aix-Marseille University, UMR 7345 CNRS PIIM, \\ équipe turbulence plasma, case 322 campus Saint Jérôme, \\ av. esc. Normandie-Niemen, 13397 Marseille cedex 20, France \\ ${ }^{3}$ Thales Electron Devices, rue Latécoère, 2, 78140 Vélizy, France
}

(Dated: March 27, 2018. Submitted. (C)The authors)

The traveling-wave tube is a critical subsystem for satellite data transmission. Its role in the history of wireless communications and in the space conquest is significant, but largely ignored, even though the device remains widely used nowadays. This paper present, albeit non-exhaustively, circumstances and contexts that led to its invention, and its part in the worldwide (in particular in Europe) expansion of TV broadcasting via microwave radiorelays and satellites. We also discuss its actual contribution to space applications and its conception. The originality of this paper comes from the wide period covered (from first slow-wave structures in 1889 to present space projects) and from connection points made between this device and commercial exploitations. The appendix deals with an intuitive pedagogical description of the wave-particle interaction.

PACS numbers: 01.65.+g (History of science), 84.40.Fe (Microwave tubes), 52.40.Mj (Particle beam interaction in plasmas)

Keywords: Traveling-wave tube (TWT), history, telecommunication, invention, radio, satellite, microwave radio-relay, wave-particle interaction.

\footnotetext{
* Electronic address: damien.minenna@univ-amu.fr
} 


\section{INTRODUCTION}

On November 12, 2014, the space probe Rosetta, built by the European Space Agency (ESA), detached its lander module Philae which performed the first successful landing on a comet, more than 475 million kilometres away from the Earth. This historic achievement was met thanks to years developing critical systems of the probe, like solar cells, trajectory computer, or propulsion parts. Yet the success of a mission depends crucially on the spacecraft capacity to transmit data across the vacuum of space. Messages must contain enough information, and must be sent with enough power to be captured on the ground, but avoid spending too much electric power, which is scarce in space. Such communication systems from Rosetta enabled us to receive scientific data to understand the history of the solar system as well as stunning images of the comet.

Telecommunication subsystems are mainly composed by an antenna, a receiver and a transmitter. Inside the transmitter, we need a device that amplifies radio-waves enough for us to communicate with spacecrafts, even at more than billions of kilometres - like with the probes Voyager 1 or New Horizons, discussed below. This wave amplifier meets a large number of criteria to be operational in space. For data emission, it needs to reach high signal amplitude with very low noise, and also needs a large bandwidth at high frequency corresponding to the amount of transmitted information. Lastly, this device needs to resist the shocks of its rocket launch and to operate for years in the dangers of space, in particular aggressive radiations.

All those conditions are fulfilled by the traveling-wave tube (TWT). Its apparition was followed by the expansion of long-range communications with the worldwide development of TV broadcasting since the 1950s, and multiplication of telecom satellites since the 1960s. Today, this device remains at the cutting edge, and still contributes to transmissions for major satellites and space probes.

Traveling-wave tubes ${ }^{1}$ (see figure 1) are electronic tubes (a.k.a. vacuum electron devices or thermionic valves) [Faillon 2008, Gilmour 2011] used to amplify radio-waves, and have a lot of applications, like radar, electronic warfare, television or radio broadcasting, Internet, sending data from space probes, planes and ships transponders, GPS, and imaging devices, or even studying the scientific characterisation of plasmas. Like all other vacuum electron devices, it is based on the momentum transfer — similar to kinetic energy transfer - from accelerated electrons to a radiofrequency wave via an interaction in a vacuum environment (see appendix A). When combined

\footnotetext{
${ }^{1}$ In the past, they were sometimes called forward-wave tubes, or traveling-wave valves. Also, some authors write "travelling" in British English with a double 1.
} 


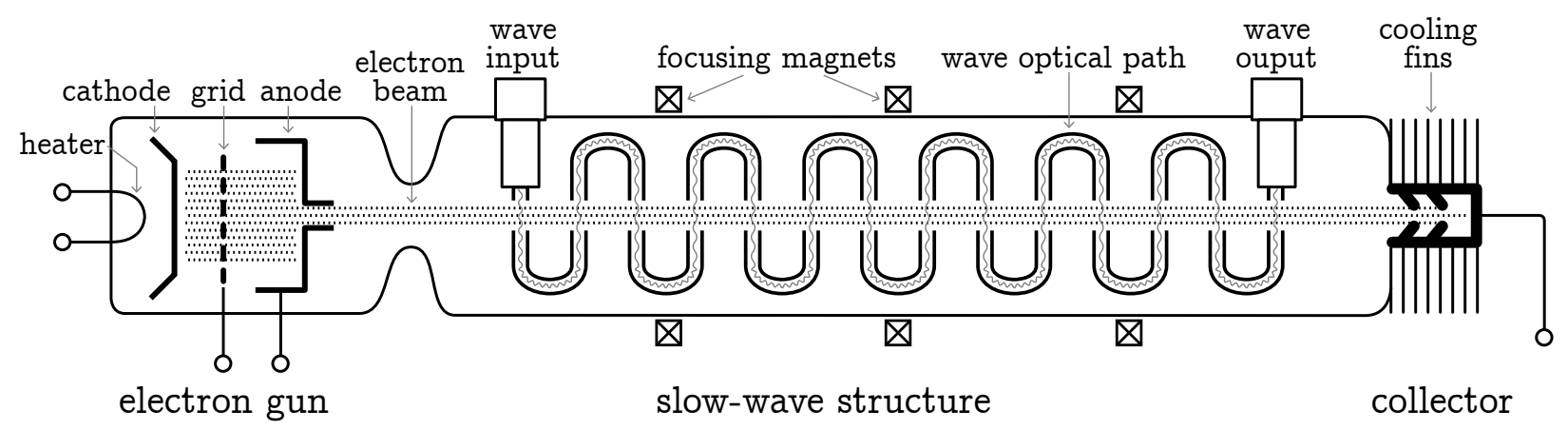

Figure 1. The traveling-wave tube is a simple electrical equipment comprising three parts: An electron gun that emits the beam; a delay line - also called a slow-wave structure - where the signal travels and where the wave-particle interaction is performed; a collector to take back the energy of electrons and limit losses. All those parts are under an extremely high vacuum. Beam focusing magnets — or periodic permanent magnet (PPM) - keep electrons moving on the longitudinal axis. In space traveling-wave tubes, the optical path is a metallic helix, as shown in figure 2 the schematic here displays a folded waveguide. Space tubes are 10-30 centimetres long. For higher frequency regimes, one uses shorter tubes, but they are harder to assemble.

with a power supply, TWTs are preferably called traveling-wave tube amplifiers (TWTAs). They are not the most powerful of vacuum electron devices, but their main features are their large bandwidth and their excellent power efficiency: ideal for long-range communications. Combined with their robustness, their high power and their long lifespan, traveling-wave tubes became quickly indispensable for space programs.

\section{WIRELESS SIGNALS BEFORE 1945}

The history of wireless communications $2^{2}$ started long before the invention of the traveling-wave tube. It all begun in 1888, when the German physicist Heinrich R. Hertz observed experimentally the propagation of electromagnetic waves in the air for the first time [Hertz 1888], twenty years after they were theorized by the Scottish mathematician and physicist James Clerk Maxwell [Maxwell 1865]. Six years later, the Italian Guglielmo Marconi built one of the first radio transmitters with a range of a hundred meters. With his Wireless Telegraph \& Signal Company, Marconi realized a cross-Channel radio-telegraphic transmission in 1899, then a transatlantic emission in 1901 [Coe 1961]. At this time, all intercontinental telecommunications were performed thanks to

\footnotetext{
${ }^{2}$ In fact, long-range communications began a long time ago with smoke signals, drums, whistled languages, beacons, semaphore, etc.
} 
submarine telegraph cables [Schwartz 2008]. Marconi's ambition was to build a global wireless network to rival with cables. He started to open communication stations, but he immediately faced competition when electrical equipment manufacturers and some countries started their own developments. Indeed, to help the German navy, Siemens and the Allgemeine Elektricitäts-Gesellschaft (AEG) were encouraged to create the radio company Telefunken in 1903. That same year, Gustave A. Ferrié performed long-distance radio experiments $3^{3}$ at the top of the Eiffel tower [Ferrié 1911. Thereafter, in 1915, the first transatlantic telephony call is achieved by AT\& $\mathbb{1}^{4}$, between Arlington, Virginia and the Eiffel Tower, followed by a call between Arlington and Honolulu.

Marconi's first successful transatlantic message, sent out more than $3500 \mathrm{~km}$ away, had raised some interrogations regarding the curvature of the Earth's surface. Indeed, it would require two towers $550 \mathrm{~km}$ tall (or one $900 \mathrm{~km}$ tall) to have a direct visual connection between both stations. Actually, the Earth's ionosphere plays an important role because it reflects waves with a frequency lower than $300 \mathrm{MHz}$, wiping out limitations due to our planet curvature, thus allowing longrange emissions. Reflections occurred in one of the layers of the atmosphere composed of ions called the Kennelly-Heaviside layer (100 km above the ground) and theorized separately by Arthur E. Kennelly Kennelly 1902, and Oliver Heaviside [Heaviside 1902]. It was thanks to this property that the British Broadcasting Corporation (BBC) was able to broadcast radio from London over Europe during World War II, without any facilities on the Old Continent. But this application is extremely sensitive to weather conditions.

On the other hand, the history of vacuum electron devices started in the late $19^{\text {th }}$ century with the discovery of thermionic emission - the electron flux emission coming from heated metal filaments - utilized for incandescent light bulb\$5. In 1904, the English physicist Sir John A. Fleming, while working for the Marconi company, used this effect to detect radio waves and built the first vacuum tube: the Fleming valve (a.k.a. the vacuum diode) Fleming 1905]. But the first practical tube is credited to the American Lee de Forest when he built, in 1906, a triode (named "audion"), which was able to better receive, radiate and amplify electromagnetic signals [Forest 1908]. As electromagnetic waves were also reflected by metallic surfaces, as proved by Hertz, another major application of vacuum tubes was radar (RAdio Detection And Ranging) operations. Patents about

\footnotetext{
${ }^{3}$ Unintentionally, Ferrié experiments granted an important usefulness to the Iron Lady and protected it from its scheduled demolition. The Eiffel Tower became and still is an important radio station. Before him, Eugène Adrien Ducretet performed, in 1898, a sound emission by wireless waves between the Eiffel tower and the Panthéon, 4 km away [Eiffel 1900].

${ }^{4}$ One of the pioneers of telephony, the Scot Alexander Graham Bell, founded the Bell Telephone Company in 1877.

The company became the American Telephone \& Telegraph Company (AT\&T) in 1885, and was at times the world's largest telephone company.

${ }^{5}$ The same kind of light bulbs used for domestic consumption during the $19^{\text {th }}$ and $20^{\text {th }}$ centuries.
} 
radars were filed during the 1900s, but it is only in the 1930s and the 1940s that they began to gain in importance for military applications. Long-range detection of small objects (boats or planes) requires to broadcast strong electromagnetic powers that only magnetrons —another kind of vacuum electron device - were able to generate at the moment. During the Second World War, radars made thanks to the magnetron were one major element of the Allies' victory.

Between the two World Wars, television broadcasting begun timidly to emerge to the general public. For instance, $\mathrm{RCA}^{6}$ is known to have broadcast [Goldsmith 1946] the first TV programs for New Yorkers on April 30, 1939, from the top of the Empire State Building in New York City and from a series of relay stations spanning the length of Long Island. But instead of telegraphy and low definition radio, applications for a large number of telephone calls simultaneously or TV emissions need larger flows of information sent, requiring wireless signals with higher frequencies. And for those higher frequencies (above $300 \mathrm{MHz}$ ), the ionosphere does not reflect the waves 7 any more, imposing the use of relays for line-of-sight propagation to compensate for the Earth curvature. Moreover, the range and the noise of amplifiers limited the expansion of telephones and TV by Hertzian-waves, until the appearance of better devices.

\section{INVENTIONS OF THE TRAVELING-WAVE TUBE}

Fatherhood of the traveling-wave tube (TWT), as we know it today, is most often granted to an Austrian refugee, Rudolf Kompfner in 1942 —notably after his public announcement in 1946 - when he was secretly working on microwave vacuum tubes for the British Admiralty at the University of Birmingham during World War II. But the history of this device is more complex because the traveling-wave tube was, consecutively, discovered thrice independently. In fact, two fundamental concepts were needed to conceive a TWT: the slowing-down of electromagnetic waves, and the addition of an electron beam inside the tube to have the wave-particle interaction.

One year after his extraordinary discovery that electromagnetic waves can propagate in the air, Hertz, scrupulous to get on with his studies, did the earliest work [Hertz 1889] on electromagnetic wave-guides: structures that confine and guide waves. Investigating the velocity of waves, he realized they could be steered along metallic guides. Because of the increase of their optical path,

${ }^{6}$ The Radio Corporation of America (RCA) was formerly the American Marconi, a subsidiary of the British Marconi Company before 1919.

${ }^{7}$ In fact, microwaves (from $300 \mathrm{MHz}$ to $300 \mathrm{GHz}$ ) are slightly reflected by the troposphere $(15 \mathrm{~km})$. This effect, discovered in the 1950s Booker 1950, was used to increase the range of radio-relays, but it needed powerful amplifiers and huge antennas. 
waves will take more time to cross the guide than if they were going straight, hence Hertzian-waves are slowed down, and such frameworks are called slow-wave structures or delay-lines. Hertz built the first metallic helical wave-guide in 1889: "I [Hertz] rolled a wire 40 metres long into a spiral $1 \mathrm{~cm}$ in diameter, and so tightly that the length of the spiral was 1.6 metre" [Hertz 1893, p. 158]. It was a simple coil where waves were 5 times slower along the guide longitudinal axis. But the slow-wave structure alone cannot provide any wave amplification without an electron beam. Also, Hertz' pioneer achievement on wave-guides was paltry compared to the theoretical works performed by three English physicists: Sir Joseph J. Thomson [Thomson 1893, Lord Rayleigh Rayleigh 1897, and Henry C. Pocklington Pocklington 1897. They have been followed by few other authors early in the $20^{\text {th }}$ century, but only the development of traveling-wave tubes in the 1950s increased the interest for the helical structure. Other forms of slow-wave structures were also designed in parallel with the development of earliest radio sets, mostly in the 1930s, when klystrons and magnetrons, two kind of vacuum electron tubes, appeared. However, the helix guides (see figure 2) still remain the most used structure for space TWTs because they allow broader bandwidth than others, meaning higher flows of information.

To build a traveling-wave tube, we need another fundamental idea: adding an electron beam to the slow-wave structure in a vacuum tube, which enables the wave amplification. This idea was recognized in 1933 by the Russian Andrei V. Haeff, a young researcher of the California Institute of Technology (Caltech), inspired after watching surfers on Santa Monica Beach, California; he concluded that the surfboard speed and the wave velocity had to match so the surfer can properly use the wave energy Copeland 2015b. In his first patent [Haeff 1936], Haeff described a device "for generating, controlling and measuring extremely high frequency waves", to which he refers sometimes by the term "travelling waves". His device used two parallel helical slow-wave structures with an electron beam flowing between them: it was the first traveling-wave tube, even though its slow-wave structure looks unusual. It seems that Haeff used his TWT to build a portable radio transmitter and receiver operating at $750 \mathrm{MHz}$. But at this time, electron guns were not good enough to provide an efficient focusing of the beam, so his device was not very efficient. The next year, Haeff joined the Radio Corporation of America (RCA) at Harrison, New Jersey, and sold them his patent, but the corporation did not permit Haeff to develop his invention further, and his discovery was largely ignored.

Meanwhile in the Netherlands, the traveling-wave interaction principle was the first time appre- 
ciated theoretically by Klaas Posthumus at the Philips NatLab 8 (Eindhoven) when investigating the newly-invented magnetron Posthumus 1935. He found that the axial component of the rotating wave velocity was synchronised with the average speed of electrons. As a result, the electron energy was transferred to the wave and amplified it.

The variety of early microwave devices built before 1945 is astonishing, and some inventors came very close to make a TWT. The American researcher Frederick B. Llewellyn, working at Bell Labs 9 , proposed a patent 10 Llewellyn 1945 in 1940. His amplifier was built "to secure a useful cooperative relation between the alternating electric field within the guide and electrons traversing that field". However, Llewellyn's invention was not really a TWT because his folded wave-guide - a kind of delay line comparable to the one sketched by the figure 1 - was closed in two spots at the middle of the tube, making his invention working more like a klystron with two (very long) cavities having some aspects of a TWT.

The second time the traveling-wave tube was invented was in 1940 by the Swedish research physicist Nils E. Lindenblad when working at Rocky Point, New York. This time, the patent Lindenblad 1942] proposed a modified version of Haeff's tube, to put the electron beam inside through a helix slow-wave structure. Lindenblad designed the first modern version of the helix traveling-wave tube as we know it today and introduced it as a "device capable of efficiently amplifying a wide band of frequencies such as would be demanded by a multichannel radio relay amplifier". In his patent, the basics of TWTs are well understood: "the speed of electrons [...] is made to be substantially equal to the axial velocity of propagation of the electromagnetic wave". Lindenblad estimated possible to amplify a frequency band from 30 to $390 \mathrm{MHz}$ without any important variations over the band. In addition, he also recognized that the pitch (the gap $d$ in figure 2 of the helix can be modified to maintain synchronism with the electron beam. As electrons lose velocity inside the tube, the pitch is decreased to slow-down the electromagnetic wave, so the amplification can be performed during a longer time: a method now often used and called "taper" or "pitch tapering".

${ }^{8}$ To avoid depending on third-party patents, Gerard and Anton Philips established in 1914 their company's own "Physics Laboratory", which turned into a world class fundamental and applied research facility, growing to over 2000 employees in the 1970s. Breakthroughs and achievements at the Nat(uurkundig) Lab(oratorium) include nonlinear dynamics (Balthasar van der Pol), quantum physics (Hendrik Casimir), magnetic resonance imaging, audio cassettes and the compact disc Philips 2014.

9 The Bell Telephone Laboratories Gertner 2012, now Nokia Bell Labs, were founded in 1925 by AT\&T and the Western Electric as a independent division to conduct research and development. These laboratories are famous worldwide for their numerous contributions in telephony, TV, space communications, information theory, radio astronomy, mathematics, computer science, etc., and are associated with the discovery of transistors, photovoltaic cells, CCD captors, or optical fibers. They have also employed a lot of famous award-winning researchers including eight Nobel prizes and three Turing awards.

10 In fact the use of wave-electron interaction 


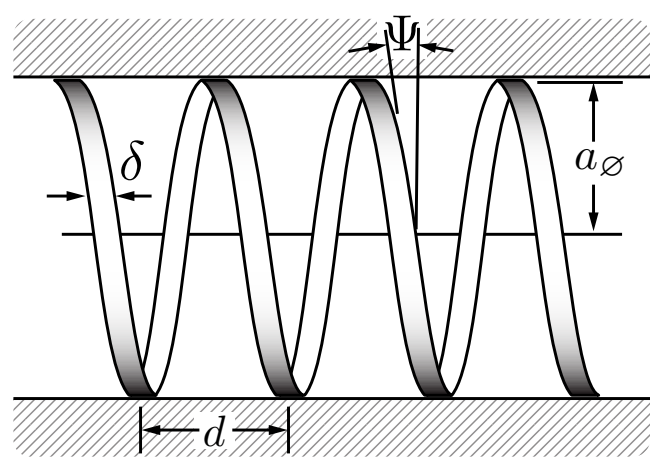

Figure 2. The slow-wave structure is used to elongate the optical path of waves. For a helix, waves are slowed down by a factor $2 \pi a_{\varnothing} / d$. In space tubes, this represents generally one-tenth of the speed of light. The geometry of the slow-wave structure is chosen to match the wave velocity with the electron speed: there is resonance, and some momentum of the electrons can be transferred to the wave for amplification.

But Lindenblad's discovery is controversial because he was an antenna specialist at RCA at the same time as Haeff, and their labs were about $100 \mathrm{~km}$ apart, though there is no evidence that they ever met Copeland 2015b. And more curious is the fact that it was the same attorney who filed both their patents for the RCA, but the one by Haeff was never cited in Lindenblad's patent of 1940. The lack of theoretical models about TWTs and the significantly different designs of both inventions could explain why Lindenblad did not refer to Haeff. However, after the rise of the TWT popularity, Lindenblad filed a new patent Lindenblad 1951] in June 1947, this time with a reference to Haeff's one. Regardless of this anecdote, early works of Haefi11 and Lindenblad ${ }^{12}$ on travelingwave tubes were never really recognized nor used, and are only mentioned in very few historical accounts [Wathen 1954], nor referred as TWTs [Pierce 1947a, Warnecke 1956, Pierce 1962].

As previously stated, the traveling-wave tube was then rediscovered a third time by Kompfner in late 1942 at Birmingham. During wartime, the limited information exchange about radio and radar technologies might explain why the patents by Lindenblad — published in October, just a few months before - were unknown across the Atlantic. When Kompfner joined ${ }^{13}$ the Admiralty in 1941, to work on valves at the Physics Department, Birmingham University, one of his first goals was to help a team to build a klystron amplifier, which would be more sensitive — with a stronger wave-electron interaction - than the crystal-mixer receivers available at that time, with the intent

${ }^{11}$ Andrei Vasily Haeff is also known for his invention of another kind of vacuum tube: the inductive-output tube (IOT, a.k.a. the klystrode) Haeff 1939. These tubes built by RCA were used on 1939 to broadcast TV programs from the top of the Empire State Building in New York City Goldsmith 1946.

12 Nils Erik Lindenblad is credited with more than 300 patents, and is mainly known for his antennas. He developed the television antenna placed on top of the Empire State Building in 1939 Lindenblad 1939.

13 Rudolf Kompfner had a training as an architect, but he was a tinkerer with cathode-ray tubes and klystrons when he joined the Admiralty. 
to improve the range of radars. To do this, we can either increase the power output or boost the sensitivity of the receiver. After a year of working on this problem, Kompfner concluded that if the klystron was relatively inefficient and had a narrow bandwidth, it was because the device had a fundamental weakness: the coupling between the electron beam and the radio-frequency field in the resonator gaps was too weak, because electrons spent too much time in the field, losing part of the energy they had gained a little earlier, or vice-versa. Therefore, Kompfner made the brilliant suggestion to match the wave and electrons velocities. This led him to discuss with delay-line experts and to design the TWT concept. The next year, in November 1943, Kompfner used a helix as slow-wave structure to build his first traveling-wave tube with a modest power gain. Later he produced a TWT at a frequency of $3.3 \mathrm{GHz}$ with a better sensitivity than the best klystron ever built at this time Kompfner 1976.

At that moment, the TWT was still a secret device developed in wartime.

\section{PUBLIC ANNOUNCEMENT AND DEVELOPMENTS}

Kompfner moved to the Clarendon Laboratory, Oxford, in 1944, where he continued his work, aiming to find a theory that would enable design optimization. Seeing the great opportunities given by TWTs, he was helped by more and more people, including his research assistant Joseph Hatton. Visiting the Clarendon Laboratory at this time, John R. Pierce, an American researcher of Bell Labs, examined the device and realized the significance of the wide bandwidth available, ideal for microwave telecommunications. Indeed, the main purpose of Bell Labs - as part of a telephone company - was to develop communication systems, even though they also worked on radars during the war. With the aim to develop a good theory about TWTs, Pierce and Kompfner organized a partnership, then Pierce brought the concept with him to the United States.

The results of British wartime investigation on the traveling-wave tubes were presented to public announcement by Hatton at the $4^{\text {th }}$ IRE ${ }^{14}$ Electron Tube Conference at Yale University, New Haven, on June 27 and 28, 1946. Hatton described some of the British results, and later in this conference, Pierce, associated with his colleague Lester M. Field 15 , revealed how far the research at Bell Labs had progressed. Since the IRE conferences had a good reputation among electrical

${ }^{14}$ In 1963, the Institute of Radio Engineers (IRE) merged with the American Institute of Electrical Engineers to became the Institute of Electrical and Electronics Engineers (IEEE).

15 Lester M. Field was employed at Bell Labs for only two years, between 1944 to 1946, after his Ph.D. Thereafter, he joined Stanford university, and became, in four years, its youngest professor at the age of 32 . He was one of the founders of the Electronics Research Laboratory at Stanford. This lab was well known for TWT research. After a transition by Caltech, he became vice-president and associate director of the Hughes Research Laboratories (HRL) where he was involved in TWT developments and in space programs. 
engineers, the discovery became immediately famous in the sphere of vacuum electron devices, and Kompfner's name became inseparable from his invention. After the conference, worldwide task forces of industrial and research labs started to develop their own versions of tubes. For instance, in the Soviet Union, teams of young military servicemen started to better understand the electronwave theory and to build TWTs; but due to the Cold War, their advancement stayed barely known beyond the Iron Curtain Loshakov 1949, CIA 1953, Pchelnikov 2003.

A few days after the announcement, The New York Times ostentatiously reported the possibility to send ten thousands phone calls at once by "a device that eventually may provide the means of setting up more channels for long-distance communications than they will know what to do with" and "it is expected to do as much for the future of very-highfrequency [sic] nationwide communication as the deForest 'audion' did for the broadcast and world-wide telephony and telegraphy pioneers" Kennedy 1946.

In August 1946, the first general description TWTs appeared [Barton 1946], followed the next months by articles [Rockett 1946, Whitmore 1946, Wildhack 1946] in a few journals of electronics. In November, Kompfner published Kompfner 1946] an introduction about his invention in the journal Wireless World ${ }^{16}$, followed by Pierce the next month [Pierce 1946] in the Bell Labs Record. The world's first peer-reviewed publication on a TWT theory was submitted, in December 1946, by two French researchers, André Blanc-Lapierre and Pierre Lapostolle Blanc-Lapierre 1946 of CNET $^{17}$, immediately followed by Jean Bernier [Bernier 1947] of CSF ${ }^{18}$ in January 1947 and by Pierce and Field [Pierce 1947a, Pierce 1947b] in February. By the end of 1950, probably a hundred papers and patents had been published about the new tube. A famous textbook Pierce 1950], written by Pierce and still a classic, established the robust basis of the device. Since then, research and development to improve tubes never stopped.

The traveling-wave tube brought many benefits from the point of view of electrical laboratories. Performance showed the device to be more suitable for telecommunication usages than other vacuum tubes, at a period where powerful means of message transmission were needed (see next section). And, for academic purpose, all the theoretical study was to do. But its main advantage

16 The British electronics journal Wireless World - very popular among amateurs and professionals of audio and electronic devices - was originally published by the Marconi Company under the name The Marconigraph from 1911 to 1913 . Since 1984, it is renamed the Electronics World.

17 The Centre National d'Études des Télécommunications (CNET) was an independent division of the Postes, Télégraphes et Téléphones (PTT) administration (nowadays Orange).

18 The French Compagnie Générale des Téléphonies sans Fils (CSF) was founded in 1918 by Emile Girardeau —a former member of Ferrié's team - to compensate the lack of French radio companies, and probably because the army bought equipments only from legal business entities. CSF became Thomson-CSF in 1968 after merging with the Compagnie Française Thomson-Houston (CFTH). CFTH was also one of the early companies to investigate TWTs Roubine 1947. In 2000, the group became Thales after another merger with AEG-Telefunken. Their tube 
was that, as a new device, each competitors were on equal terms, even small ones. It was for those reasons the French public laboratory CNET went to investigate the TWT immediately after its annoucement [Atten 1996]. But the competition was tough. Indeed, in 1947, CSF obtained the equivalent of 600000 euros (taking into account inflation) by the French Government for a market research on the new electrical equipment after announcing having made a $2.7 \mathrm{GHz}$ TWT working at $200 \mathrm{~mW}$.

In the summer of 1947, Kompfner attended to the $5^{\text {th }}$ IRE Electron Tube Conference at Syracuse University, New York. At this conference, he discovered TWT had become an important subject, both theoretical and experimental, of many laboratories and industries all over the world. He was impressed by advancements achieved, but also worried Kompfner 1976 that the researches in the United Kingdom on these subjects had not progressed as much. After returning to his country, Kompfner with British Admiralty representatives aimed to report on this conference and to plead for a special effort by Britain to regain the initiative. They met the UK Coordination of Valve Development Committee (CVD) composed by government and industrial tube representatives and managed by D. C. Rogers of STC ${ }^{19}$. Aware of the benefits for communication of TWTs compared to other amplifiers, one of their research teams led by Rogers achieved Rogers 1949, Rogers 1953 an efficient $4 \mathrm{GHz}$ TWTA, which will later be used for commercial applications. Under Pierce's recommendation, Kompfner joined the Bell Labs in 1951.

In parallel, the active TWT developments led to the discovery of the backward-wave oscillator (BWO) (a.k.a. carcinotron 20 . The BWO is basically a TWT where the wave is propagated in the opposite direction to electrons. Its main use is for military scramblers. Invention of BWO was simultaneously and independently presented by Kompfner from Bell Labs, and by Bernard Epsztein from CSF, at the IRE Electron Tube Conference in Ottawa, Canada, on June 1952 Guénard 1952, Kompfner 1976. It also seems that a Soviet team secretly invented the BWO back in 1948 [Pchelnikov 2003]. In the same vein, consecutive progress to improve klystrons, in particular to expand their bandwidth, led to the invention of the extended interaction klystron (EIK) Wessel-Berg 1957, Chodorow 1961, a device - similar to the rugged coupled cavity and the interdigital line TWTs - which tries to combine the advantages of both klystrons (ruggedness, and high power capability) and TWTs (larger bandwidth).

The major advances in the United Kingdom, France, the United States, Japan and the Soviet

19 The Standard Telephones and Cables Ltd. (STC) was the British division of the Western Electric.

${ }^{20} \mathrm{CSF}$, now TED, still uses the trade-name carcinotron because of the crayfish which swims backwards (in Greek "karkinos") Guénard 1952. 
Union brought those countries to the forefront of traveling-wave tubes' manufacturing, and to their commercial applications.

\section{WIRELESS RADIO-RELAYS AFTER 1945}

After the Second World War, European countries needed to rebuild their economic power. While the priority was first given to transport grids, power generation and distribution, the transmission networks progressively gained an interest, notably under the pressure of the North Atlantic Treaty Organization (NATO), for tactical communication purposes, and because of the public's interest for a new medium shelved during the war: the television. TV emissions were retransmitted in some big cities since the 1930s, and only for a small audience, so the number of programs and channels was limited. Those transmissions were done by radio-wave from low range stations directly to the customer. But to provide TV over countries, it was needed to send the programs to each stations, and there were two available means of propagation: coaxial cables and wireless signals.

The cable option was the oldest one and has been practiced sufficiently long to be firmly established. It was the option chosen, in 1951, for the Birmingham-Manchester cable Halsey 1952. The Hertzian-wave approach was new ${ }^{21}$ to broadcast television on country-scale but was promising, and was the option taken the same year for the London-Birmingham radio-relay Clayton 1951 established with triodes. Because of the Earth curvature, this choice required relays $50-70 \mathrm{~km}$ apart.

In 1948, the British Television Advisory Committee recommended the extension of television diffusion to cover $80 \%$ of the United Kingdom. Hence, to provide TV in Scotland, the British Broadcasting Corporation (BBC) and the Post Office considered the best means of propagation was the use of wireless waves instead of cables, and they signed a contract with STC to establish the first commercial microwave radio-relay systems in the world using traveling-wave tubes Dawson 1954. The system needed to carry television signals between Manchester and the Kirk o'Shotts transmitting station, near Edinburgh, at more than $350 \mathrm{~km}$, using seven intermediate relays. The line was activated ${ }^{22}$ in August 1952, and was the first application of the, so called, super high frequency (over $3 \mathrm{GHz}$ ) outside North America [Unk. 1951, Bray 1995]. With this achievement, the traveling-wave tube demonstrated having improved performances for television signals

21 The world's first experimental microwave $(1.7 \mathrm{GHz})$ radio link was demonstrated in 1931 between Calais and Dover (40 km long) Kohlhaas 1931.

${ }^{22}$ In parallel with TWTs of STC, the microwave radio-relays between Manchester and Edinburgh used also 2 GHz triode valve amplifiers from the General Electric Company Bray 1995, but this system was later ousted by the one with TWTs. 
compared with triodes and klystrons. From 45000 television receivers in 1948, the country went to more than 2 million ones five years later, and the $80 \%$ goal was reached in 1957 .

Since at this time, the United Kingdom had been equipped with both cables and radio-relays, an early economic comparison between them was performed [Faulkner 1952] with the conclusion that, for almost the same service, the cost of the cable system was inevitably higher and required many more repeater stations than a radio-link. But cable required less maintenance charges, and unnecessary expenditure could be avoided when sharing facilities with pre-existing telephone cables. However, microwave radio-relay systems were young and steadily improved.

On the other side of the Channel, France possessed a large telephonic network composed of coaxial cables connecting big cities. Those lines were able to transmit several hundreds of phone calls, but just enough to send one TV program, and pulling additional cable for each wanted signal was an expensive option. Also, a more serious problem was the fact that those cables were designed for multichannel telephony and not well suited for TV transmission. The Postes, Télégraphes et Téléphones (PTT) administration decided to use the microwave option and they started a collaboration with CSF to upgrade the network of wireless transmission. First tests were completed in July 1951, by making the connection between Paris and a radio tower in Bois de Molle, Beauvais, $60 \mathrm{~km}$ away. The emitter provided by CSF comprised a broad bandwidth klystron to obtain a linear frequency modulation with an output at $1 \mathrm{~mW}$, then the signal was amplified by a TWT up to $1 \mathrm{~W}$ for a base frequency at $4 \mathrm{GHz}$ (similar to STC tubes). In 1953, they finished the wireless liaison between Paris and Lille, distant of $230 \mathrm{~km}$. This liaison 23 was the first in the world to provide both telephone and television using the same transmitters [Forestier 1951, Marzin 1951, Gutton 1952].

Before June 1953, the Paris-Lille liaison was extended to London and Brussels with CSF hardwares. This line and all other TV networks available in Western Europe —including cable lineswere used for the live transmission of the coronation of Queen Elisabeth II, on June 2. Broadcast ${ }^{24}$ simultaneously in at least six countries to several million of TV spectators, it was the world's first major TV event [Smith 1953]. Millions of other people were able to see the coronation after tapes were sent 25 around the world.

23 The first French wireless radio-relay of $1 \mathrm{GHz}$ with telephone commercial use was built in 1951 by the Compagnie Française Thomson-Houston (CFTH) for the Radiodiffusion - Télévision Française, from the Eiffel Tower, Paris, to the city hall belfry of Lille, with two relays Angel 1952, Martin 1952. This line did not involve TWTs and was replaced after 1953 by the other one presented.

24 The live multinational TV transmission of the coronation of Queen Elisabeth II in 1953 was organized by the European Broadcasting Union. This success led one year later to the creation of Eurovision.

25 To provide videos of the coronation to the rest of the world, and especially the Commonwealth, tapes were sent by airplane. This was a common practice until transoceanic communications by satellites were implemented. 
Table I. Commercial helix traveling-wave tubes used in early microwave radio-relays in the United Kingdom, France and the United States. The CV2188 was the first commercial tube and was used in the ManchesterEdinburgh line. The TPO 921 is the direct sucessor of the TPO 851 used in the Paris-Lille line. The type 7812 was a TWT (third stage) used on the Tokyo-Osaka line. The 444A (developed by Bell Labs) was used in the TH system covering the United States. For Color-Television (CTV), a much wider bandwidth is required than for black and white. Sources: Rogers 1953, Voge 1957b, Sawazaki 1956, McDowell 1960.

\begin{tabular}{lcccc}
\hline Manufacturer & STC & CSF & Shibaura & Western Electric \\
Name & CV2188 & TPO 921 & 7812 & $444 \mathrm{~A}$ \\
\hline Year & 1952 & after 1953 & 1954 & 1960 \\
Capacity & $1 \mathrm{TV}$ & $1 \mathrm{TV}+240 \mathrm{ph}$. & $1 \mathrm{TV}$ & $1 \mathrm{CTV}+420 \mathrm{ph}$. \\
$\quad$ & & 720 phones & Hundreds & 1860 phones \\
Frequency & $3.6-4.4 \mathrm{GHz}$ & $3.8-4.2 \mathrm{GHz}$ & $3.5-4.3 \mathrm{GHz}$ & $5.9-6.4 \mathrm{GHz}$ \\
Power Out & $2 \mathrm{~W}$ & $>2 \mathrm{~W}$ & $3.5 \mathrm{~W}$ & $5 \mathrm{~W}$ \\
Gain & $25 \mathrm{~dB}$ & $28-30 \mathrm{~dB}$ & $17 \mathrm{~dB}$ & $30 \mathrm{~dB}$ \\
Efficiency & $\approx 1 \%$ & $20 \%$ & $?$ & $23 \%$ \\
Life Time & 3500 hours thousands hours & $?$ & 10000 hours \\
\hline
\end{tabular}

On April 1954, Japan showed its advances when opening the Hertzian-wave line Tokyo-NagoyaOsaka, more than $460 \mathrm{~km}$ long. This line was established for the Broadcasting Corporation of Japan (NHK) to start regular TV emissions, and also for the Nippon Telegraph and Telephone Public Corporation (NTT) to rebuild the country's telephone service which had been wiped out (nearly $80 \%$ of the service) by bombing. It was the first microwave radio-relay system of the country and the system was equipped with three-stage TWTs working at $4 \mathrm{GHz}$ and built by the Tokyo Shibaura Electric Co —nowadays Toshiba Corporation - Nomura 1954, Sawazaki 1956, Young 1965. Ten years later, in 1964, NHK covered $81 \%$ of the Japanese population for 13 millions viewers, and NTT had 8.6 million telephones in service.

During this time, the pioneers of microwave radio-relay systems were the United States. Immediatley after the war, the urgent need to provide television throughout the country pushed AT\&T to develop their microwave radio-relay systems. But it was before first commercial TWTs, so Bell Labs began a live-demonstration by building the New York-Boston wireless line Durkee 1947, Thayer 1949, which was $350 \mathrm{~km}$ long (with eight relays), using $4 \mathrm{GHz}$ triodes [Morton 1949]. This system (called TD-2) could handle 240 (then 600) telephone channels at once and was used afterwards by AT\&T for commercial applications. In 1951, the New York-San Francisco line was 
established ${ }^{26}$ [Roetken 1951] and the system was extended to more than $70000 \mathrm{~km}$ with relays by the end of 1960. From 155000 television receivers in 1948, the country went to more than 15 million ones four years later. There are several reasons why triodes were privileged in the first instance in the United States. The main one is historical. In 1912, AT\&T had bought de Forest's triode patent, and they already used it as a repeater for the 1914 New York-San Francisco telephone cable, the world first transcontinental telephone line. Four decades of improvements in all its aspects made the triode hard to dethrone. Also early microwave tests (1945) were done before the TWTs was known. But at the end of the 1950s, the triodes were replaced by the $6 \mathrm{GHz}$ TWT newly developed by Bell Labs, carrying at least 1860 telephone channels (called TH system) McDowell 1960, Jarrett 1964.

Only 10 years after its (third) invention in 1942, the traveling-wave tube was already commercially used (cf. table $\mathbb{I}$ ), which is an exceptionally short time since the device was not really optimized at this time, and some companies had sold TWTs after only 5 years of development. Several kinds of vacuum electron tubes, like triodes, were used, but the appearance of traveling-wave tube amplifiers (TWTAs) provided large bandwidth signals ideal for long-range TV-transmission, and replaced other vacuum tubes. It was not the first vacuum tubes used for long-range communication, but it surely boosted the development of microwave radio-relay systems for television around the world between the 1950s and the 1980s. At the same time, international agreements on favored standards (including frequency band designation, see table III) were achieved by organizations from a wide range of countries including the Soviet block.

The next step was sending those relays in outer space.

\section{EXTRA-TERRESTRIAL RADIO-RELAYS}

It is hard to say with certainty who was the first person to write about communications in space. Probably inspired by the 1865 novel From the Earth to the Moon by Jules Verne Verne 1865, and of Percival Lowell's books [Lowell 1896, Lowell 1906] dealing with Martian life, the Soviet sciencefiction writer Aleksey N. Tolstoy (a remote relative of Leo) wrote Aelita in 1923, a novel about explorers leaving the Earth with a rocket and finding Atlantean descendants on Mars [Tolstoy 1985. The novel was adapted, a year later, in a silent film with the same title. Not written in the novel,

\footnotetext{
${ }^{26}$ The line was $4700 \mathrm{~km}$ long with 117 stations about $52 \mathrm{~km}$ apart and cost 380 million dollars (with inflation).
} 
the film's narrative thread is the moment when every radio stations on Earth receive the same message from Mars: "Anta... Odeli... Uta".

On the other side of the world, in the United States, the science-fiction writer Hugo Gernsback published a serious seminal article titled Can we radio the planets? [Gernsback 1927]. In this article, he wrongly assumed that if the Earth, meteors and stars are composed predominantly of iron, then the Moon should be too, and according to Hertz works "it would therefore make an excellent reflecting medium". So, he proposed to use the Moon as a reflector to determine the existence of the Kennelly-Heaviside layer and he dealt with interplanetary emission. This was followed, two years later, by a study from a geophysicist on commercial Hertzian-wave propagation on the Mars ionosphere [Hulburt 1929].

Inspired by Gernsback's work, a few papers [Mofenson 1946, Grieg 1948 proved the feasibility of using the Moon as passive reflector, like a mirror, to achieve transcontinental communication, leading later to the first signals sent and received through space [Gootée 1946]. In the early 1950s, the U.S. Naval Research Laboratory (NRL) developed the Communication Moon Relay project (a.k.a. Operation Moon Bounce) [Butrica 1997] and they transmitted the first vocal message in space sent back to Earth, on July 24, 1954. At this time, ground stations used $10 \mathrm{~kW}$ klystron amplifiers. This project was used in 1959 by the U.S. Navy, in a context of cold war, to create a backup line between Washington, D.C. and Hawaii or U.S. fleets. Indeed, ionospheric storms could cut off radio transmissions. The system 27 was made public in 1960 . But this concept was difficult to implement because the distance and the weak fraction of radiation reflected off the Moon, impose powerful devices, making TV transmissions difficult. In addition, there is a 2.5 seconds delay to send any signal - too much for telephone conversations - not to mention the fact that the Moon is visible only up to twelve hours a day. In conclusion, our natural satellite was not a perfect relay but it gave the idea to use much closer reflectors.

Twelve years before the launch of the satellite Sputnik 1, the British scientist and science-fiction writer Sir Arthur C. Clarke ${ }^{28}$ wrote two papers ; the first one was private Clarke 1945b] and only given to his colleagues at the British Interplanetary Society, while the other was published Clarke 1945c in the journal Wireless World, titled "Extra-Terrestrial Relays", and both dealt

27 The Communication Moon Relay project was originally from a classified program of espionage, the Passive Moon Relay (PAMOR), to monitor Soviet communications reflected on our natural satellite Butrica 1997.

${ }^{28}$ Sir Arthur Charles Clarke's vision of the space conquest was inspired by traumatic $V$-2 rockets developed during World War II. Before writing on space stations for telecommunications, he wrote another article Clarke 1945a in Wireless World to propose a peaceful use of those $V$ - 2 at geosynchronous orbit (GSO) for research on the ionosphere. Indeed, the space race started immediately after the war, when the United States and the Soviet Union collected as many $V$-2 rockets as possible and captured German scientists. 
with the usefulness of putting satellites at a geosynchronous orbit (GSO) for communications. GSO (a.k.a. Clarke orbit) was imagined by the Russian theorist Konstantin E. Tsiolkovsky ${ }^{29}$, who proved that an object orbiting at $36000 \mathrm{~km}$ above the equator would appear as stationary from the Earth, because its orbital period is 24 hours. For comparison, at $400 \mathrm{~km}$, objects have a period of an hour and a half, while the Moon, at $362000 \mathrm{~km}$, has a period of 28 days. Clarke's revolutionary idea was to place on this orbit three space stations covering all the planet, intended for censorshipfree global TV and radio-telephones. Since those objects stay in the sky at the same point, it is easy to point an antenna at them. In Clarke's proposals, space stations worked via some "solar engines" and were regularly supplied from Earth. Clarke estimated that GSO could be reached by artificial crafts in perhaps half a century ahead. While the publication of his article did not collect much audience in 1945, the appearance of the first satellites made Clarke famous 30 as a pioneer in the domain.

The next year, in May 1946, the members of the Project RAND 31 , working for the U.S. Army Air Force, started to investigate Clarke's ideas. They wrote a complete report Project RAND 1946. Davies 1988 dealing with GSO satellites as relays for communications, but also included aspects on military applications, scientific research, weather reconnaissance, interplanetary travels, and practical analysis, like orbit trajectories and payload available. They estimated that this achievement would bear considerable repercussions to the world, comparable to the Wright brothers' success, or the explosion of the atomic bomb. But the initiative to build the first communication spacecrafts came from civilian commercial investigations.

Meanwhile, Pierce was also known — under the pseudonym J. J. Coupling - as a science-fiction writer and a precursor in the field of space communications. He wrote a novel mentioning the possibility of reflecting radio-waves from the Moon and interplanetary radio signals [Pierce 1952b]. Just after, he started to seriously work on his ideas with his colleagues at Bell Labs. In 1955, he proposed [Pierce 1955] the first paper addressing the economic viability for orbital radio-relays. At this time, AT\&T and the British Post Office were building the first transatlantic telecommunications cable (TAT-1) [Schwartz 2008], providing 36 telephone channels all at once, where existing cables were only for telegraph. TAT-1 was inaugurated in 1956 and costed approximatively 42 million dollars. Pierce analysed that to provide one television signal — or 1080 telephone channels - across the

${ }^{29}$ Konstantin Eduardovich Tsiolkovsky is considered as one of the fathers of modern astronautics for his theoretical developments, and was a science-fiction writer. In addition with geosynchronous orbit, he is also granted for the rocket equation and for the multistage rocket concept, a key element in the success of Sputnik 1.

${ }^{30}$ His article Clarke 1945c became so popular that it was reprinted in the centenary issue of the Electronics World Josifovska 2013. (formerly Wireless World) as one of the most influent paper of the journal.

31 "Research ANd Development", now the RAND Corporation, is an American think tank founded by the U.S. Army Air Force and the Douglas Aircraft Company. 
ocean, you would need a billion dollars or more to put additional cables. If building a spacecraft is worth this billion, then the concept appeared immediately more suitable. Pierce estimated that relays in space would not compete with microwave radio-relays over land, but would certainly be feasible for transoceanic communication. In his proposal, satellites are not at the geosynchronous orbit (GSO), but instead, are at a lower height called Low Earth Orbit (LEO), imposing for communications to wait until satellites appear overhead emitters and receivers. To remedy the lack of permanent link with the ground, the system needs several other identical satellites - a configuration called a satellite constellation - to ensure that at least one satellite be visible at any time. LEO crafts can be sent with smaller rockets or carry heavier payloads. Pierce also mentioned the possibility to use either passive crafts to reflect signals, like with simple spherical mirrors, or active crafts where signals are re-amplified before being sent back.

The idea for extra-terrestrial relays was established and only needed a remarkable instigation to appear.

\section{FIRST COMMUNICATION SATELLITES}

On October 4, 1957, the Soviet Union reached the outer space with the first man-made object orbiting ${ }^{32}$ around Earth, the satellite Sputnik 1, launched from Tyuratam. Because it was orbiting at very low height, a repetitive steady beep, emitted from a 20-40 MHz pentode, was receivable by any radio amateurs throughout the world. There is no doubt the Soviet achievement was the disruptive element that started the space race once for all in the United States. It led to the first American satellite Explorer 1 launched in February 1958 from Cape Canaveral, Florida. Less than three years later, more than a hundred objects had been launched ${ }^{33}$ into space, successfully or not, by Soviets and Americans.

The Echo project, started in 1956 by the National Advisory Committee for Aeronautics (NACA), was originally a mission to measure the density of the upper atmosphere by observing a 3.5 metres diameter balloon-like satellite. During the U.S. Sputnik crisis in 1958, NACA was dissolved to become the National Aeronautics and Space Administration (NASA). At this

32 The $V$-2 rockets, used in the 1940s by German, then after the war by American, British, and Soviet, were probably the first man-made objects in space but they were not orbiting. They also took the first Earth pictures and videos White 1952.

${ }^{33}$ For instance, American sent SCORE (Signal Communications by Orbiting Relay Equipment) in December 1958. The satellite carried a recorded voice message from President Eisenhower, continuously emitted like the Sputnik beep. But the device was not a relay for live telecommunication. In April 1960, the American TIROS-1 (for Television Infrared Observation Satellite) became the world's first weather satellite. The craft was composed of two cameras sending down videos of the Earth Logsdon 1995. 
time, Pierce and Kompfner — after he joined Bell Labs in 1951 — realized that it would be possible to use spherical mirrors as passive reflectors to test space communications. NASA accepted this suggestion, and the Echo project became NASA's first communications satellite project. On August 12, 1960, they launched a plastic sphere, with aluminized surface, named Echo 1, large of 30 metres in diameter. It became the first artificial satellite that actually relayed a real-time voice message, from Holmde ${ }^{34}$ New Jersey to Nançay (near Bourges), France. It was a passive object because there were no electronic systems to amplify the signal aboard. The success of Echo 1 proved it was possible to send a message through space via man-made relays. However, the limited communication capacity of a single voice channel highlighted that passive reflectors would not have a lot of applications. A similar project between the same stations was also being conducted using the Moon as a passive reflector. Those two projects were crucial to the improvement of tracking techniques - Echo 1 was visible and usable as relay only 5 minutes per passage over the Atlanticand ground station equipments. Also, while ground stations at this time used klystrons as power amplifiers, these were quickly replaced by TWTs for the Telstar project.

Thereafter, to demonstrate the reliability of the active satellite, and to keep their advantage in long distance communications, AT\&T and Bell Labs approved the Telstar project initiated by Pierce, Kompfner, and some or their colleagues at Bell [Crawford 1963. Like Clarke's idea, an active relay would amplify signals before sending them back to Earth. But reaching the geosynchronous orbit seemed too difficult for the researchers, instead Telstar satellites were planned for a low altitude orbit (LEO), like Echo 1, so they could only be seen, at the same moment, by two ground stations for a maximum of twenty minutes across the Atlantic, with an orbital period of 2.5 hours around our planet. The original idea was to make fifty five satellites (a constellation) to cover almost the entire Earth surface, linked with twenty five ground stations at any time. Pierce estimated an expense of 500 million dollars. Telstar satellites were nearly spherical polyhedra of 88 centimetres diameter for 77 kilograms. They were composed of the new technology required for satellite communication, like thousands of transistors for other various electric systems, solar cells for power generation, and a $4 \mathrm{GHz}$ helix traveling-wave tube amplifier from Bell Labs [Bodmer 1963]. In fact, all the satellite's active elements were solid-state devices (transistors) excepted for the TWT amplifier. On the U.S. East coast, Bell Labs built a ground station at Andover, Maine. On the European side, a French-British rivalry led to the construction of two ground stations, one at Goonhilly Downs, Cornwall, by the British Post Office, and one at

${ }^{34}$ The Bell Labs horn antenna of Holmdel, built in 1959 to support the Echo project, is also famous because of its association with the discovery of the cosmic microwave background, the oldest light in the universe, by Bell Labs employees A. Penzias and R. Wilson who were awarded the Nobel Prize in 1978. 
Pleumeur-Bodov ${ }^{35}$, Brittany, by the French PTT. All three ground stations exploited a $2 \mathrm{~kW}$ TWT with coupled cavities as slow-wave structure Collier 1963. Telstar 1, launched on July 10, 1962, was the world's first active satellite for telecommunication, and transmitting ${ }^{36}$ television across the Atlantic Ocean. In her following Christmas message, Queen Elizabeth II mentioned that "this tiny satellite has become the invisible focus of a million eyes" [Titchmarsh 2013. After this success, scientific, engineering, financial and political forces moved forward in developments for satellite communications which also increased the interest of TWTs.

Just five months later, on December 14, 1962, NASA launched Relay 1, a similar satellite with the same features as Telstar 1 but built $[37$ by RCA and with a longer lifetime in orbit. Relay 1 was the first satellite to broadcast between the United States and Japan. The spacecraft is also known for its large number of recorded anomalies, including the 60 minutes time to warm up the traveling-wave tube (usually it was only taking around 3 minutes) Butrica 1997.

On another hand, Haeff — after he left RCA to briefly join the U.S. Naval Research Laboratory (NRL) - joined the Hughes Research Laboratories (HRL) of the Hughes Aircraft Company ${ }^{38}$ in 1950, and became rapidly vice president and director of research 39 in the company. Hughes was developing their own TWTs, and it was more and more interested in the space conquest.

When Pierce and Kompfner were conceptualizing Echo and Telstar projects, they published, in 1959, an article [Pierce 1959b] in the Proceedings of the IRE giving their view of transoceanic communication. For them, a constellation of at least twenty four active satellites orbiting at LEO height would be enough to cover the world. This vision was not shared by Harold A. Rosen, an electrical researcher at Hughes. Unaware of Clarke's work, for him the future of satellite communication was achievable by reaching the geosynchronous orbit (GSO). Agreeing with him, Haeff formed a task force, led by Rosen, to initiate the Syncom design. Unlike low orbit, to reach GSO, one must drastically reduce the weight of the launched object. A part of the Syncom success was due to the lightweight traveling-wave tube built by John T. Mende 40 at Hughes, with

35 The antenna of Pleumeur-Bodou, France, used for Telstar 1 signals was completed on July 7, 1962, viz. three days before the launch of the spacecraft.

36 The first transmission by Telstar 1 on July 10, 1962, is a telephone conversation between the chairman of AT\&T and Vice President Johnson, from Andover to Washington. This was followed by TV emission from the United States to France. France sent back footage of Yves Montand interpreting "la Chansonnette", while across the Channel, Britain sent back a color test card (the world's first transatlantic color transmission). Then America and Europe sent each other various videos and messages, like footages of Mount Rushmore, the Statue of Liberty, the Eiffel Tower, or a base-ball match and a declaration of President John F. Kennedy, broadcast to the public by local television organizations.

37 When NASA initiated the Relay project, AT\&T and Hughes Aircraft Company tried to win the contract to build the two spacecrafts but finally NASA selected RCA.

38 The Electron Dynamics Division, of the Hughes Research Laboratories (HRL) of the Hughes Aircraft Company, 
a weight of half a kilogram Highstrete 1962. The total mass of the spacecraft was less than $40 \mathrm{~kg}$, compared to the $170 \mathrm{~kg}$ of Telstar 1. Following an enthusiastic report on the feasibility of the project, Hughes Aircraft Company funded its construction, and after a previous failure, Syncom 2 became on July 26, 1963, the first geosynchronous satellite; it was equipped with Hughes' TWTs. The major advantage of a geosynchronous satellite is that ground station can keep the link with the satellite at any time, easing the tracking. In 1964, Syncom 3 orbited over a sustained period of time, and transmitted the Summer Olympics from Tokyo to the United States.

Understanding the huge impact of those new orbital radio-relays, the U.S. government funded, in August 1962, the Communications Satellite Corporation (Comsat), a government-owned telecommunication company recognized by western countries. Its first satellite Intelsat 1 (a.k.a. Early Bird) was the world's first commercial communications satellite. Built by the Hughes Aircraft Company, it was launched in April 1965 on a GSO. The next step for those satellites was to increase their area capability, with more powerful amplifiers with a wider bandwidth. The second series of Intelsat crafts integrate a multiple-access capability by carrying four $6 \mathrm{~W}$ traveling-wave tubes for each spacecraft that could operate simultaneously. But when Comsat was funded, President Kennedy gave it the monopoly on space transmissions [Butrica 1997]. AT\&T's Telstar project 41 immediately vanished because Comsat only bought satellites from the Hughes Aircraft Company, preferring the GSO configuration.

\footnotetext{
41 Bell Labs designed and built six Telstar spacecrafts, but only two were launched. NASA negotiated an excellent deal with AT\&T because NASA's contribution to the project was limited to launch services, but they claimed the project to be supported by them, and they even published results of the experiment as a NASA publication, while it was originally issued as articles in the Bell Telephone technical journal.
} 
Table II. Example of helix space traveling-wave tubes used in early satellites. The M4041 was the first TWT in space. Applications Technology Satellites (ATS) were NASA's experimental probes based on Syncom design. Sources: Feldman 1965, NASA 1963a, NASA 1963b, NASA 1965, Kornfeld 2001].

\begin{tabular}{lcccc}
\hline Manufacturer & Bell Labs & RCA & Hugues & AEG-Telefunken \\
Name & M4041 & A-1245 & $384 \mathrm{H}$ & TL 4003 \\
Satellite & Telstar 1 & Relay 1 & ATS 1 & Symphonie A \\
\hline Launched & 1962 & 1962 & 1966 & 1973 \\
Frequency & $3.7-4.2 \mathrm{GHz}$ & $4.05-4.25 \mathrm{GHz}$ & $3.96-4.12 \mathrm{GHz}$ & $3.7-4.2 \mathrm{GHz}$ \\
Output Power & $2 \mathrm{~W}$ & $11 \mathrm{~W}$ & $4 \mathrm{~W}$ & $13 \mathrm{~W}$ \\
Gain & $40 \mathrm{~dB}$ & $35 \mathrm{~dB}$ & $36-40 \mathrm{~dB}$ & $46 \mathrm{~dB}$ \\
Efficiency & $<10 \%$ & $12 \%$ & $?$ & $34 \%$ \\
Mass & $>1000 \mathrm{~g}$ & $<2000 \mathrm{~g}$ & $<567 \mathrm{~g}$ & $640 \mathrm{~g}$ \\
Life Time & $100000 \mathrm{hours}$ & $>5$ years & $50000 \mathrm{hours}$ & $?$ \\
\hline
\end{tabular}

In the Soviet block, telecom satellites started with Molniya 1-1, launched less than three weeks after Early Bird, in 1965. This satellite and its successors were put on elliptical orbits called Molniya orbits — one category of Highly Elliptical Earth Orbit (HEO) — with a center largely shifted from Earth, enabling them to appear over northern latitudes most of the day.

Table III. Microwave bands of frequencies (also referred as hyper-frequencies, or centimetre and millimetre waves) from IEEE standards IEEE 2003 established in 1976. Higher frequency enables larger flow of information, but are more subject to atmospheric attenuation. Present satellites operate from L to KaBand.

\begin{tabular}{r|ccccc}
\hline Band & L-Band & S-Band & C-Band & X-Band & Ku-Band \\
GHz & 1 to 2 & 2 to 4 & 4 to 8 & 8 to 12 & 12 to 18 \\
Band & K-Band & Ka-Band & Q-Band & V-Band & W-Band \\
GHz & 18 to 26.5 & 26.5 to 40 & 33 to 50 & 40 to 75 & 75 to 110 \\
\hline
\end{tabular}

It is not a coincidence that the main U.S. manufacturers of traveling-wave tubes (Bell Labs, RCA, and Hughes) at this time, were also those who supplied space communication devices. Researchers who developed TWTs were conscious this device - reliable, effective and light - was perfectly adapted for the space conquest ${ }^{42}$ (cf. table II . Progressively, transcontinental telephone ${ }^{42}$ To reach the Moon, Apollo's Command Modules (CSM) were equipped with S-Band TWTAs Baldwin 1968, Rosenberg 1972. 
and television communications were enabled everywhere, including specialized satellites, like for maritime ships or airplanes (Inmarsat), and Direct-to-Home TV broadcasting (Intelsat, Eutelsat, Galaxy, Astra), and new services, like satellite phones (Iridium, Globalstar), GPS (cited below), Internet access by satellite (Wildblue, $K A-S A T$ ), or numerical radio diffusion (XM Radio, Sirius). They also offered high-definition images of the Earth, including contributions in weather science, and images of solar system objects. In the same time, Rosen ${ }^{43}$, Clarke 4 and Pierce ${ }^{45}$ started to share the title of "fathers of satellite communications".

\section{THE EUROPEAN SPACE CONQUEST}

Four days after the launch of Telstar 1 in 1962, a few western European countries joined the space conquest race by signing an agreement to establish two new space agencies: the European Space Research Organisation (ESRO) which would build scientific probes, and the European Launcher Development Organisation (ELDO) which would focus on a launcher. But those agencies fell behind for many reasons, like the number of member states with different space policies and budgets, or the issue of users. Indeed, since western Europe is relatively small and not crossed by an ocean, a large telecommunication program could be considered as a superfluous luxury compared to terrestrial options. Meanwhile, some European countries progressed with theirs own finance: 46 . Until 1975, ESRO built eight scientific satellites — one failure due to the rocket — sent by American rockets. Indeed, ELDO had a series of failures in attempting to develop a European launcher. This led to the merging of ESRO and ELDO, to create the European Space Agency (ESA) in 1975. Since then, they continued the quest for a launcher with the Ariane project.

During the 1960s, President de Gaulle and Chancellor Adenauer had acted for French-German cooperation. To balance the communication monopoly of the two superpowers, a consortium was created between French and German organisations; Symphonie A was launched on Decem-

${ }^{43}$ Harold Allen Rosen won, in 1995, with Pierce, the Charles Stark Draper Prize for "development of communication satellite technology". He was involved with the majority of Comsat crafts built after the 1960s for Hughes Aircraft Company, and then the Boeing Company.

${ }^{44}$ Writer of almost 100 books, Clarke is one of the most influential science-fiction authors of his time with Robert Heinlein and Isaac Asimov. The world remembers him mainly as the writer of 2001: A Space Odyssey, simultaneously published and released as a movie by Stanley Kubrick in 1968.

${ }^{45}$ In addition to TWTs, satellite communications and science-fictions, his pioneering spirit brought John Robinson Pierce to contribute in information theory with Claude E. Shannon, and in music theory. With his colleague Max Mathews and others, they released Music from Mathematics, an album completely played by an IBM 7090 computer. One of their songs, Daisy Bell (a.k.a. Bicycle Built for Two), was later interpreted by the fictitious artificial intelligence HAL 9000, in Stanley Kubrick's 2001: A Space Odyssey. He is also the neologist of the term "transistor". Beside computing science, transistors can be used as solid-state power amplifiers (SSPAs), and ironically are the main competitors of vacuum electron tubes. 
ber 19, 1974, with the American rocket Delta, from Cape Canaveral, Florida, and became the first European satellite for telecommunication. The $13 \mathrm{~W}$ TWTAs - the first space TWTs built in Europe 47 - working in C-Band (see table III) were provided by the German AEG-Telefunken company. Just after, the newly merged ESA financed a series of two experimental telecommunication satellites called Orbital Test Satellite (OTS), and equipped with Ku-Band TWTAs from the French Thomson-CSF. After a failure of the rocket, OTS-2 was put in GSO in 1978. The consequence of this demonstration was the creation in 1977 of the intergovernmental European Telecommunications Satellite Organization (Eutelsat) to develop space communication in Europe, financed at $60 \%$ by ESA [Butrica 1997]. Eutelsat started operations using in first instance OTS crafts with ESA consent, then brought its own satellites. The OTS program served as the forerunner of the European Communication Satellite $(E S C)$, with four satellites launched in the 80s, including ESC-1 launched with the new European Ariane 1 launcher.

In the continuation of Symphonie A, another French-German consortium was created to develop TV broadcasting in the two countries. Between 1987 and 1990, they successfully launched four satellites: TDF 1 and 2 for France, and TV-SAT 1 and 2 for Germany. Each was sent into GSO using Ariane 2 and 4 launchers. TDF 1 was equipped with $240 \mathrm{~W} \mathrm{Ku-Band} \mathrm{TWTAs} \mathrm{from}$ Thomson-CSF, the most powerful tube at this time. In comparison, currently state-of-the-art KuBand TWTAs work at $200 \mathrm{~W}$ maximum. Operators do not need more power, mainly thanks to improvements in antennas.

Meanwhile, Japan had also joined the party as another foreign competitor for the United States and Europe. In February 1983, the National Space Development Agency of Japan (NASDA) launched Sakura 2a (a.k.a. CS-2a), the first commercial (and civilian) satellite equipped with Ka-Band TWTAs, using a Japanese $N$-II rocket.

\section{PRESENT SPACE USES OF TRAVELING-WAVE TUBES}

In 2017, we celebrated the sixtieth anniversary of Sputnik 1 and the beginning of the space conquest. The traveling-wave tube is still widely used in satellites and scientific spacecrafts, even though solid-state power amplifiers (SSPAs) have gained importance and could compete with them nowaday, especially for amplifiers below and up to C-Band. Nowadays, the two dominant man-

47 Before that, there were other European vacuum electron tubes in space, like the $10 \mathrm{~W}$ output, S-Band triodes from Siemens — escorting Hughes' TWTs — in the NASA's Mariner program Feldman 1965, Kosmahl 1982. Mariner 2 is the first probe to achieve a planetary flyby (Venus), followed by Mariner 4 (Mars) and Mariner 10 (Mercury) Siddiqi 2002. 
ufacturers on the space TWT market are the French-German Thales Electron Devices (TED) - formely Thomson-CSF and AEG-Telefunken- (cf. table IV) and the American L3 Electron Devices - formely Hughes. The Nippon Electric Corporation (NEC) was another important player until it stopped their space tubes commercialisation in the end of the 1990s. The Indian CEERI also entered the competition in 2012, as well as the Chinese BVERI.

Table IV. Examples of recent helix space traveling-wave tubes manufactured by Thales Electron Devices, and used in current satellites. The TH 4626, and the TH 4606C will respectively be installed on the JamesWebb Space Telescope and the probe BepiColombo. For each ones, the life time is estimated to more than 15 years. Sources: Dürr 2015, Gastaud 2014, Barsotti 2018, Thales].

\begin{tabular}{lcccccc}
\hline Name & TL 4150 & TH 4795 & TH 4816 & TH 4626 & TH $4606 \mathrm{C}$ & THL40040CC \\
\hline GHz & $3.4-4.2$ & $10.7-12.75$ & $17.3-20.2$ & $\sim 26$ & 32 & $37.5-42.5$ \\
$P_{\text {out }}$ & $150 \mathrm{~W}$ & $150 \mathrm{~W}$ & $160 \mathrm{~W}$ & $50 \mathrm{~W}$ & $35 \mathrm{~W}$ & $40 \mathrm{~W}$ \\
Gain & $50 \mathrm{~dB}$ & $>50 \mathrm{~dB}$ & $>50 \mathrm{~dB}$ & $>50 \mathrm{~dB}$ & $>50 \mathrm{~dB}$ & $48 \mathrm{~dB}$ \\
Eff. & $73 \%$ & $68 \%$ & $63 \%$ & $55 \%$ & $54 \%$ & $50 \%$ \\
Mass & $1000 \mathrm{~g}$ & $800 \mathrm{~g}$ & $900 \mathrm{~g}$ & $700 \mathrm{~g}$ & $700 \mathrm{~g}$ & $<890 \mathrm{~g}$ \\
\hline
\end{tabular}

The Global Positioning System (GPS), initiated by the U.S. government for military operations, became freely available ${ }^{48}$ for civilian use in 1983. GPS is currently achieved by a constellation of thirty-one satellites orbiting on Medium Earth orbits (MEO) situated between LEO and GSO, and using only solid-state power amplifiers (SSPAs) because it does not need large data transmissions. However, there exist other global navigation satellite systems to balance the American monopoly and which all use TWTs, like the fifteen Galileo satellites — and ten others scheduled-, financed by the European Union and launched by ESA, or the Chinese BeiDou-2, the Indian IRNSS, and the Japanese QZSS. Indeed, in the L-Band, SSPAs and TWTAs have similar RF performances — but SSPAs are smaller and less expensive.

The technological revolution of the early $21^{\text {st }}$ century is undisputably the Internet. If the main traffic of the net is sent though cable or optical fibre, however, communication satellites were early used to connect isolated big city hubs (important nodes), which redistribute the flux to individual homes and offices. One of major issues of the Internet is the global cover of rural areas. Some programs try to remedy this, like the French THD-Sat Project, financed by the

${ }^{48}$ GPS was allowed for civilian air lines in 1983 by president Reagan after a Boeing 747 of the Korean Air Lines was shot down by the Soviet Air Force in the Sea of Japan. A navigation error conducted the plane to trespass the Soviet prohibited airspace. 
French government and carried out by CNES, in order to develop the products and technologies dedicated to a new generation of satellites for high throughput Internet access. In particular, THD-SAT is supporting the development of two space TWTAs from TED, one $170 \mathrm{~W}$ in Ka-Band for direct communication to individual homes and a second one of $40 \mathrm{~W}$ in Q-Band [Barsotti 2018] for the satellite transmission toward anchor stations. This project is a forerunner of space Q-Band applications.

In 2017, we also celebrate the 40 years of the launch of twin probes Voyager. Voyager 1 is performing its journey at more than 21 billion kilometres from Earth - 140 times the SunEarth distance, viz. more than 4 times the Sun-Neptune distance, the longest telecommunication range ever done - and is currently the farthest man-made object still in communication with us thanks to its three TWTAs built by Watkins-Johnson 49, one in the S-Band, and two in the XBand [NASA 1977]. The signal takes 19 hours to reach us from the probe, and is captured by a worldwide network of tracking facilities belonging to the NASA Deep Space Network. Her sister Voyager 2 made a detour near ice giants Uranus and Neptune - the only spacecraft to have ever visited them - and is only more than 17 billion kilometres from Earth (or 16 light-hours away). Even now, the probes regularly send us data about cosmic rays or sun magnetometry. Between them flies Pioneer 10 - sent with two $8 \mathrm{~W}$ TWTs working at $2.3 \mathrm{GHz}$ Siegmeth 1973 - but NASA lost communication with the probe in January 2003.

The majority of deep space missions were, are and will be equipped with TWTAs. As a nonexhaustive list, we can mention the following explorer probes:

- Giotto sent in 1985 - terminated in 1992 - by ESA to fly by the Halley comet;

- Cassini/Huygens sent in 1997 — terminated in 2017- by NASA, ESA and the Italian Space Agency (ASI) to study Saturn, its rings and its countless moons, and which stepped on Titan;

- Rosetta/Philae sent in 2004 - terminated in 2016 - by ESA which landed on the 67P/ChuryumovGerasimenko comet;

- Venus Express sent in 2005 — terminated in 2015 - by ESA to explore Venus;

49 The Watkins-Johnson Company was founded in 1957 by Dean A. Watkins, a former professor of electrical engineering at Stanford University, and Horace R. Johnson, a former head of Hughes Aircraft Company's microwave laboratory Grant 1996. 
- New Horizon sent in 2006 by NASA to observe the dwarf planet Pluto ; a flyby of one Kuiper belt object is scheduled for 2019;

- $M A V E N$ sent in 2013 by NASA to study the Mars atmosphere;

- OSIRIS-REx sent in 2016 by NASA to bring samples from an asteroid;

- BepiColombo scheduled for 2018 by ESA and the Japan Aerospace Exploration Agency (JAXA formely NASDA) to observe Mercury;

- Solar Orbiter scheduled for 2019 by ESA and NASA to investigate the heliosphere and solar wind.

The Hubble Space Telescope is one of the most precious tools for astronomers since 1990, because it is not affected by the atmosphere. Developed by NASA and ESA, it has largely contributed to increase our knowledge on lots of domains in astrophysics and cosmology, like on our solar system, stellar evolutions, interstellar medium, far away galaxies, exoplanets, the supermassive black hole at the center of our galaxy, or the accelerated expansion of the universe. Hubble is orbiting at LEO height $(600 \mathrm{~km})$ and uses solid-state amplifiers. But its successor, the James-Webb Space Telescope (JWST or Webb) scheduled for launch in 2018, and developed by NASA, ESA and the Canadian Space Agency (CSA), will use Ka-Band traveling-wave tubes from TED. Webb will be positioned at about 151.1 million kilometres from us, in a Sun-Earth Lagrangian point, a privileged spot for observation. If we compare the contribution of Hubble, with its 2.5 meter wide mirror, with promises of $W e b b$ and its mirror of 6.5 meter, we cannot conceive yet the tremendous scientific contribution which this new satellite will bring, transmitted to Earth thanks to TWTs.

Because of the Earth curvature, keeping a continuous link between objects at LEO and their operation centres is not possible. During the 1980s, NASA started to launch the Tracking and Data Relay Satellite (TDRS) system, a constellation of ten GSO satellites - the last one, TDRS-M, was sent on August 18, 2017- assembled with Ku-Band TWTs, and allowing a permanent coverage for selected missions at LEO. Main representative missions are the Hubble Space Telescope and the International Space Station (ISS), both equipped with solid-state amplifiers, and before them, the system was operating for the Space Shuttle program. TDRS satellites act as relay satellites, always keeping the space-to-ground connection with stations. The rock star of this system was TDRS1, launched on April 1983, which was the first satellite able to see both Poles simultaneously, performing the first Pole-to-Pole call, and was providing most of the TDRS coverag $₫ 50$. Originally

\footnotetext{
${ }^{50}$ The second TDRS satellite was destroyed on January 28, 1986 in the Space Shuttle Challenger explosion.
} 
planned for a duration of 7 years, TDRS-1 was in operation for 27 years, until its last travelingwave tube failed [Zaleski 2011], leaving the craft unable to operate its retransmission activities and expediting its retirement.

Most of recent LEO constellations do not use any TWTs. Solid state power amplifiers (SSPAs) grabbed their share of this market since they are cheaper than vacuum electronics. OneWeb constellation (to be launched in a few years) designed with more than eight hundred satellites to global Internet distribution, will work with Ku-Band SSPAs. The first generation of the O3b constellation 51 providing Internet between the two tropics, were equipped with Ka-Band TWTs. However, its second generation used SSPAs. But SSPAs cannot yet reach the high power and/or high frequencies available with TWTs, like for most of GSO program and deep space missions with high data traffic required. Besides, there still are recent satellite families at LEO using TWTs like Earth observation programs - like the Sentinel missions sent by ESA or the Canadian Radarsat52 made by CSA - , meteorological programs - like ESA's MetOp satellites—, or the CryoSat program of ESA to measure the thickness of polar ices.

Besides, almost all ground stations in contact with spacecrafts use TWTs or klystrons.

\section{CONCEPTION OF TRAVELING-WAVE TUBES}

There exist numerous amplifiers from vacuum tubes, like triodes, magnetrons or klystrons, to solid-state power amplifiers (SSPAs), like transistors. A popular misconception claims tubes to be under threat of extinction for the benefit of solid-state electronics. While this is true in computers and modern domestic electronics - except for microwave ovens - , this is plainly false in space applications. TWTs provide a crucial service to space telecommunication and have continuously been improved. There is no perfect amplifier for all needed applications, but there are better ones depending on their performances, their cost and their operating regimes, and traveling-wave-tube amplifiers still dominate satellite communications.

The number of space TWTs produced each year depends on the number of satellites launched. Since 2010, there were approximatively twenty GSO satellites sent per year, and a communication satellite contains between fifty to sixty amplifiers. Consequently, there are between five hundred to two thousand space TWTs produced per year. The first manufacturer is Thales Electron Devices

51 The $O 3 b$ constellation was referring to the "Other 3 billion" people without Internet access at that time.

${ }^{52}$ In addition to TWTs for communication, Radarsat-2 is equipped with enhanced interaction klystrons (EIK) for tomography. 
(TED) with two-thirds of the market share, followed by L3 Electron Devices with the remaining third.

We believe that the traveling-wave tube can be considered as the purest microwave device due to its harmonic way of using the wave-particle interaction (see appendix A). It is also probably the hardest vacuum tube to build due to the Swiss watch precision required for highly rugged elements. The choice of an amplifier is determined by four main characteristics (in importance order): reliability, performance, weight, and price. Current space TWTs prices range from 40000 to 150000 euros depending on the precision of the device - high frequencies need smaller slowwave structures. Production of traveling-wave tubes requires handicraft methods. Manufacturing is divided in two parts separated by the device pumping. The upstream part is the assembly of the diverse components and takes one to two months. Then, an ultra high vacuum — beyond $10^{-8} \mathrm{~Pa}-$ is obtained with pumps while heating tubes to over $500^{\circ} \mathrm{C}$. Finally, the downstream part consists in adjustment to fix the device — all TWTs are unique-, measurements to know characteristics of each tube, and finally, a burn-in process where devices are tested under various conditions - like vibrations, vacuum environment, or long runs of functioning. This part takes five to six months.

The traveling-wave tube is still the most efficient device when one wants to reach high power and/or high efficiency in space telecom. For the moment, it is more expensive to use SSPAs above the Ku-Band instead of TWTs. Of course, in the future, development of better SSPA 53 will border the separation between the two, but vacuum valves, especially TWTs, have not yet reached the limit of their improvements. Several paths for optimization can be taken considering the three parts of TWTs.

As presented by tables I. II and IV] TWTs have been dynamically improved over the years (see [Kornfeld 2001]). Compared to their historical debut, engineers have increased the number of collectors to three, then four, and now five, with a massive progression of the efficiency. In addition, thanks to the invention of radiation cooling, TWTs are probably the only electronic component operating up to $200^{\circ} \mathrm{C}$. And, the linearized TWTs, which appeared in the 1990s, fully compensate for the tube higher non-linearity. Also, the power flexibility of the device allows remote control of the output power from the ground.

How the electron gun injects exactly the electron beam is still under investigation. The number of particles imposes the use of powerful computers. The type of slow-wave structures can also

\footnotetext{
${ }^{53}$ Space SSPAs have some advantage, like a noise factor around $5 \mathrm{~dB}$, compared to $30 \mathrm{~dB}$ for space TWTs.
} 
be improved (including materials used) to optimize the momentum conversion from electrons to the electromagnetic wave. Indeed, only a quarter of the beam power is transferred. The rest of it needs to be recovered, lest it will become unwanted thermal power - heating a TWT modifies its performances. So the last part to be improved is the depressed collector that determines the efficiency of the TWT. In addition, a better understanding of nonlinear effects occurring with high amplifications is required to maximize the interaction and to grasp the wave output modulation - the most important factor in current complex signal transmissions.

\section{OTHER APPLICATIONS OF TRAVELING-WAVE TUBES}

Furthermore, traveling-wave tubes have other applications than space ones. In addition to ground-to-space transmissions, the device still has some use in telecommunication, including transponders for high frequency military bands. Also, TWTs can be found in command-guidance systems for missiles and in electronic countermeasures (ECM). While this article is focused on its amplification role, the traveling-wave tube can also be used as a radar transmitter: the role for which Kompfner worked on valves. For those applications, the slow-wave structure can be replaced with coupled cavities or folded wave-guides, and the tube can be a few metres long.

Engineers in microwave radio-relays (still used nowadays) replaced TWTs in stations built from the 1950 s to the 1990 s, by solid-state power amplifiers over time. Simultaneously, those relays faced the competition with satellite communications, improved cables, and recent optical fibres. But tubes are not gone in data transfers since TWTs can reach higher frequencies. For the new $5^{\text {th }}$ generation mobile networks, abbreviated $5 \mathrm{G}$, the TWEETHER project is funded by the European Union, aiming to create state-of-the-art W-Band TWTs, based on a folded wave-guide slow-wave structure. In addition, several research groups aim to build terahertz TWTs (the record is probably $1.03 \mathrm{THz}$ so far [Tucek 2016]).

TWTs represent an important part of the vacuum devices market. In 1995, the total worldwide sales of all microwave tubes were estimated at 780 million dollars (taking into account inflation), and over half of it were for TWTs (410 million dollars) [DoD 1997]. This was, and still is, due to the price of TWTs, from a few thousand to several hundred thousand dollars. In comparison, simple low power magnetrons, like those in microwave ovens for the general public, are relatively inexpensive (a few dollars).

Since the beginning of the space race, a large number of objects are orbiting for centuries in our close neighbourhood. Collisions between them have already occurred, creating large fields 
of debris, which might make it impossible to achieve any new space mission. For example, on August 25, 2017, the Indonesian satellite Telkom 1, orbiting at GSO, was struck by an unknown object generating a large cloud of debris. This incident caused the breakdown of 12000 cash dispensers in the Indonesian archipelago [Unk. 2017]. To track the hundreds of thousand crafts and debris in orbit, space agencies have started numerous programs to catalogue them to keep space clean. As an example, ESA collaborates with the Research Establishment for Applied Science (FGAN), Wachtberg, Germany, which have the Tracking and Imaging Radar (TIRA) facility. This installation possesses a high-resolution $\mathrm{Ku}$-Band imaging radar, including a traveling-wave tube, to photograph large objects and verify their integrity [Mehrholz 2002].

Traveling-wave tubes have also a role in plasma physics. A plasma is a noisy medium and is hard to control and to analyse. Researchers at the University of California, San Diego, noted that a helix slow-wave structure can behave analogously to a plasma. To study self-consistent and nonlinear effects (e.g. trapping) of electrons in plasma waves, they built [Dimonte 1977, Tsunoda 1987] in 1976 a huge TWT, 2.7 meters long, with 2.1 centimetres diameter and 1 millimetre pitch for frequencies around $50 \mathrm{MHz}$. Later, a team from CNRS \& Aix-Marseille University, brought forward the idea, this time to investigate the chaos transition occurring in plasma physics Guyomarc'h 1996 , Doveil 2007. Their tube, still used, is one of the longest TWTs for civil use in the world with its 4 meters - long enough to need magnets to compensate for the Earth magnetic field.

\section{CONCLUSION}

The same year Telstar 1 reached posterity, Clarke claimed, with his Third Law, that "any sufficiently advanced technology is indistinguishable from magic" [Clarke 1973]. If long-distance communication seemed impossible a hundred years ago, the traveling-wave tube made it possible from outer space.

The traveling-wave tube is one of the most appropriate vacuum electron tubes in the field of telecommunication. Conceiving one requires the precision of a goldsmith and to appreciate the exchange of momentum between electromagnetic waves and electrons (see Appendix A). Relaying on decades of progress in delay-lines and thermionic valves, Haeff, Lindenblad and Kompfner were successively able to understand the intuitive basis of this process. They imagined a device where the electron beam accompanied the wave by making their velocities almost equal.

Since then, TWTs appeared on the majority of spacecrafts; from LEO research probes, to deep space missions, and GSO communication satellites. Numerous people and organizations took part 
in their development and expansion. The tube is still at the cutting edge of space power amplifiers and will certainly continue for several decades ; their remote future will depend on further researches to enhance its competitiveness. As the challenges continue to grow with space exploration reaching always further, or Internet creating always more data, the research and industrial communities are still very active to improve them.

But back in the 1950s, a lot of vacuum tube designs were available. Yet, in less than two decades, the TWT was on every continent and even in space. Its success was due to many factors. The early researches, lead by Kompfner and Pierce, showed encouraging results and were announced at popular conferences and journals among electrical engineers. The devices they built were able to generate waves at high power and high frequencies, but mainly they had large bandwidths for low noise levels, making TWTs a perfect choice for the new requests on communication systems. Consequently, a lot of competitors appeared, allowing a quick development of the device through all of its aspects. Most important, the device appeared in peace time, at the time when people were interested by the emergence of the television. Between the 1950s and the 1980s, the appearance of microwave radio-relays, made thanks to TWTs, created one of the first public global networks across continents.

Extension of this network was possible via space. During the end of the 1950s, and after attempts at using the Moon as a relay, Clarke, Pierce, and Rosen put forward fundamental ideas to develop communication satellites. The traveling-wave tube was certainly a part of the success, since it allowed satellites to be cost-effective. Successive accomplishments of Telstar 1, Relay 1, and Syncom 2 and 3, proved the considerable advantage of space communications and drew mandkind into a new era.

\section{APPENDIX A: THE WAVE-PARTICLE INTERACTION}

Predictions about wave-matter interactions occurring in traveling-wave tubes are made with the same tools as to study plasma evolutions, because the electron beam is a plasma itself with a single species. Basically, there are three model classes 54 . fluid, kinetic (like Vlasovian description) and $N$-body descriptions, each with a wide range of different models and variations. We choose to focus on the latter like [Elskens 2003] from a hamiltonian approach. In the particle description (a.k.a. discrete particle or finite $N$ description), each particle of the system is governed by elementary

\footnotetext{
${ }^{54}$ Quantum effects are not significant in space TWTs since electron energies are not high enough.
} 


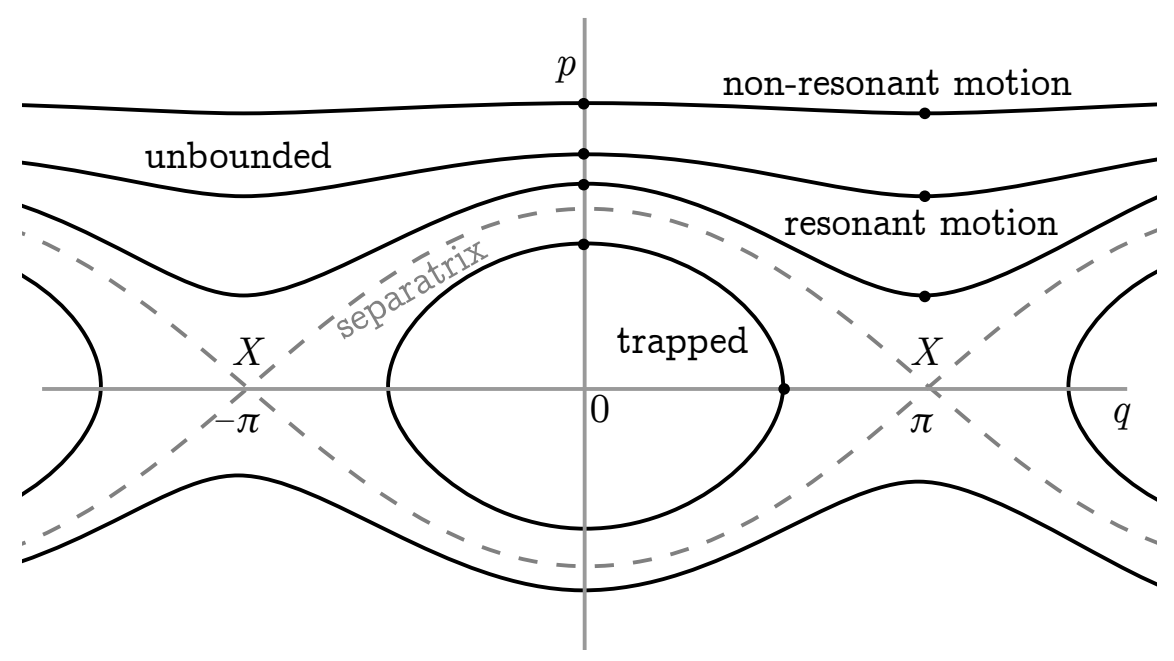

Figure 3. Pendulum phase portrait $(p, q)$ of the wave-electron interaction. The width of the cat's eye enclosed by the separatrix (dashed curve) is proportional to $\sqrt{U}$. This portrait is in the reference frame of the wave, so $p=0$ correspond to synchronism with the wave. The further a particle momentum is from $p=0$, the less its dynamics is affected. A resonant motion occurs when the particle dynamics is significantly affected by the wave (when both wave and particles velocities match), viz. in the range $|p| \lesssim 3 \sqrt{U}$.

mechanics (like the Lorentz force). Discrete $N$-body description for $N \rightarrow \infty$ become continuous distribution functions within the kinetic picture [Elskens 2014]. The $N$-body description is hardly ever used to describe the beam in TWTs for it involves an enormous number of degrees of freedom, which increases its computing costs and running time excessively. However, this description $[55$ is a remarkably intuitive way to represent wave-particle dynamics.

We start from a system composed of a single charged particle with coordinate $z=q / k$ and momentum $p$, subject to a sinusoidal electrostatic potentia $\sqrt{56}$ with wavenumber $k$. The equation of motion of this particle reads

$$
\ddot{q}=-k U \sin q
$$

with $U>0$. This system obeys the same mathematical relation as the nonlinear pendulum if we ${ }^{55}$ The particle description is common in Free Electron Laser (FEL) characterization (see Bonifacio 1990 for such description and Pellegrini 2012 for a historical review on FELs). It is also used to study Hamiltonian chaos (see [Escande 2010] and the historical review [Escande 2017]) and the laser-plasma interaction (see Bénisti 2016]).

56 Indeed, we consider an electron beam with initial speed $v_{\mathrm{el}, 0}$ near resonance with a sinusoidal electric field $E_{z}(z, t)=E_{z, 0} \sin (k z-\omega t)$ projected on the $z$-axis of the beam, with a phase velocity $v_{\mathrm{ph}}=\omega / k$, such that $v_{\mathrm{el}, 0} \simeq v_{\mathrm{ph}}$. From Newton's second law, we write the equation of motion of each electron $m_{\mathrm{e}} \ddot{z}=-|e| E_{z}$, or

$$
\ddot{z}^{\prime}=\frac{-|e| E_{z, 0}}{m_{\mathrm{e}}} \sin \left(k z^{\prime}\right),
$$

after the substitution $z^{\prime}=z-v_{\mathrm{ph}} t$ to the reference frame where the wave is immobile, with $|e|$ the elementary electric charge and $m_{\mathrm{e}}$ the electron mass. Equation (1) is the same as eq. 22 with $U=|e| E_{z, 0} / m_{\mathrm{e}}$, leading to the same phase portrait as figure 3. Acceleration areas are where $k z^{\prime} \in[-\pi+2 n \pi, 0+2 n \pi]$, with $n \in \mathbb{Z}$, and deceleration areas range where $k z^{\prime} \in[0+2 n \pi, \pi+2 n \pi]$. This effect causes a particle grouping, called electron bunching. 

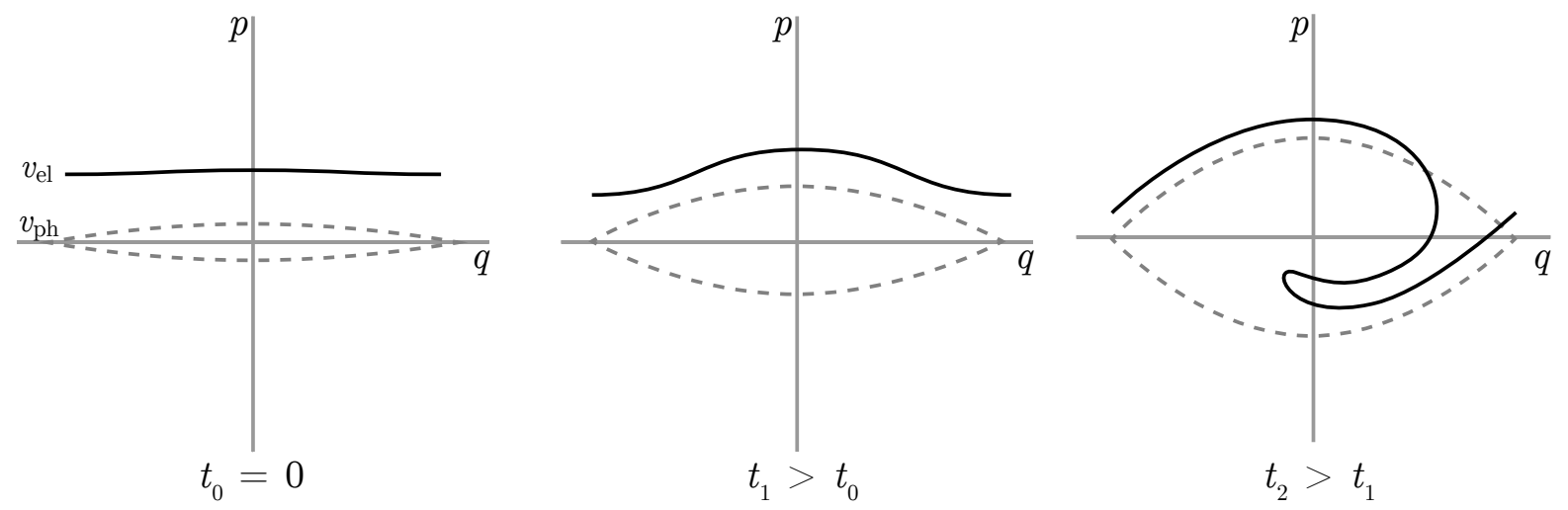

Figure 4. Wave-electron momentum exchange for a self-consistent system, inspired from Firpo 2001. The width of the cat's eye (dashed lines) is proportional to $\sqrt{U} \sim I^{1 / 4}$. At time $t_{0}$ (left panel), we consider a monokinetic beam of speed $v_{\text {el }}$ where particles are represented by the continuous black curve. We add a wave of phase velocity $v_{\mathrm{ph}} \lesssim v_{\text {el }}$, and trajectories get modulated. Some particles get accelerated by the wave, and others get decelerated; it turns out that the deceleration effect dominates the acceleration, so that the total momentum of particles decreases. This lost momentum is transferred to the wave, whose amplitude (hence the cat's eye size) increases. At later times, resp. $t_{1}$ and $t_{2}$, the wave is amplified (central panel), and this process goes on until particles get trapped, which initiates the nonlinear regime due to bunching (right panel). The reverse effect occurs if we take $v_{\mathrm{ph}} \gtrsim v_{\mathrm{el}}$ : particles will gain momentum and the wave amplitude will decrease [Doveil 2005, Escande 2010]. Remark that this example expressed the amplification in time whereas the amplification of a TWT is in space (see figure 5). For the traveling-wave tube, nonlinearity effects (as at $t_{2}$ ) have been studied since the early years [Cutler 1956].

let $k U=g / l$, with $g$ the gravity acceleration, $l$ the length of the pendulum and $q$ the angle with the vertical axis.

The kinetic energy of this particle, with its mass set to 1 , is $p^{2} / 2$; its potential energy is $-U \cos q$, and the sum of both is the total energy (namely, the hamiltonian)

$$
H(p, q)=\frac{p^{2}}{2}-U \cos q
$$

Since this hamiltonian is time-independent, it is also a constant of motion in phase space $(p, q)$. Figure 3 shows typical orbits for the particle trajectory depending on the value of $H$. If the particle is located between $q=0$ and $q=\pi$, it faces a potential barrier at $\pi$ : it is slowed-down because of the effect of the field. If the particle is located between $q=-\pi$ and $q=0$, it faces a potential well at 0 and is accelerated. Depending on the value of $H$, we have

- For $H>U$, the particle is not confined spatially and reaches all possible positions $q$. It is just like the pendulum in perpetual rotation in one direction (forward for $p>0$, backward 
for $p<0)$. Then there are two possible cases. If $H \gg U$, the particle does not "see" the field, and its momentum is barely modified. If $H \gtrsim U$, the particle is near resonance with the field: its momentum is modulated depending on the wave.

- For $-U<H<U$, the particle is trapped in the potential well and traces a closed curve in phase space which never reaches $-\pi$ and $\pi$ positions. This corresponds to the pendulum librating between two points, without having enough energy to complete a full turn. Again, one may distinguish between $1-H / U \ll 1$, in which case the particle is close to the separatrix, undergoes large momentum changes, and spends much time close to the $X$ point, and the case $1-H / U \sim O(1)$ in which the particle is "deeply trapped" and oscillates mildly around the $O$ point.

- For $H=U$, the particle is located on the separatrix which is made of two unstable orbits forming a "cat's eye" in phase space between libration and rotation motions.

However, this model is incomplete. Indeed, its neglects the wave alteration by the presence of charged particles.

A model taking into account the action of the wave on electrons and the feedback from electrons to the wave, is called self-consistent. When adding the energy of harmonic oscillators corresponding to the free oscillation of the wave, one finds a self-consistent hamiltonian like

$$
H(p, z, I, \varphi)=\sum_{r} \frac{p_{r}^{2}}{2}+\sum_{j} \omega_{j} I_{j}-\sum_{j} \sum_{r} U_{j} \cos \left(k_{j} z_{r}-\varphi_{j}\right),
$$

for waves $(j)$ and particles $(r)$, where the electrostatic energy of a wave is proportional to the square of its amplitude $U_{j} \propto \sqrt{I_{j}}$, and waves have phases $\varphi_{j}$, nominal angular frequencies $\omega_{j}=v_{\mathrm{ph}, j} k_{j}$, phase velocities $v_{\mathrm{ph}, j}$ and wavenumbers $k_{j}$. The abrupt transition between relations (3) and (4) is further detailed in Antoni 1998, Elskens 2003. As the hamiltonian (4) is invariant under time translations $\left(t^{\prime}:=t+b\right)$, the dynamics conserves total energy $H$. Since (4) is also invariant under space translations $\left(z_{r}^{\prime}:=z_{r}+c, \varphi_{j}^{\prime}:=\varphi_{j}+k_{j} c\right)$, the dynamics also conserves total momentum

$$
P=\sum_{r} p_{r}+\sum_{j} k_{j} I_{j},
$$

which is a simple sum of particle and wave momenta. The wave-electron interaction is an effect based on momentum exchange. This effect is sketched on figure 4.

The physical process in traveling-wave tubes is easy to appreciate (see figure 5). The slow-wave structure of the tube is designed to impose quasi-resonance between the phase velocity of the wave 


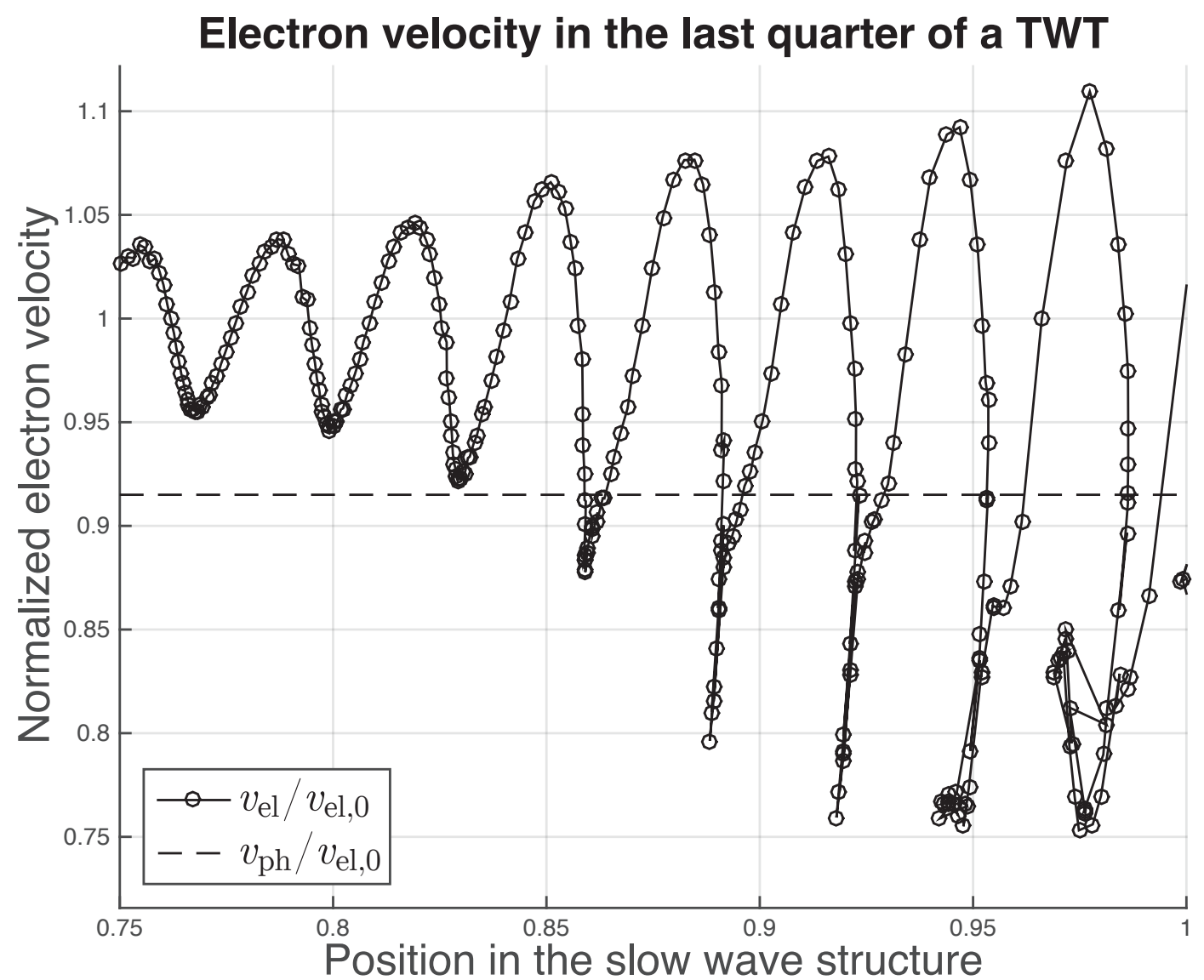

Figure 5. One-dimensional time simulation of a traveling wave tube (excluding tapers or attenuations) from a self-consistent hamiltonian model [Minenna 2017]. Initial parameters (like cathode current and potential, coupling impedances, and phase velocity) are set to ensure the amplification to reach the power saturation at the end of the tube $(z=1)$, and space charge effects are taken into account. Each dot correspond to a macro-electron (with charge $|Q| \sim 200000|e|$ ). At the beginning of the tube $(z=0$ ), all particles are emitted with the same velocity $v_{\mathrm{el}, 0}$. Particles with $v_{\mathrm{el}}<v_{\mathrm{el}, 0}$ have given their momenta to the wave, and since there are more particles below $v_{\mathrm{el}}=v_{\mathrm{el}, 0}$, then the wave is amplified. The dashed line represent the phase velocity $v_{\mathrm{ph}}$ of the wave. Nonlinear effects (trapping) start to occur approximatively when $z=0.8$ (some particles crossed the separatrix centred on $v_{\mathrm{ph}}$ ).

$v_{\text {ph }}$ along the propagation axis, and the electron speed $v_{\text {el }}$ from the electron gun. As shown on figure 2, the phase velocity in helix tubes is $v_{\mathrm{ph}} \simeq 2 \pi c a_{\varnothing} / d$, with the light celerity $c$. To obtain amplification of the wave, one just needs to ensure $v_{\mathrm{el}} \gtrsim v_{\mathrm{ph}}$. During the interaction in the tube, the total momentum (5) is conserved, so electrons on average will lose their momentum for the benefit of the wave. This effect is linear (because the amplification gain is linear) until particles have lost enough momentum for crossing the separatrix in their individual $(z, p)$ space and become trapped. 
More realistic models can contain in particular the space charge effect (viz. the Coulombian effect): electrons repel each other since they have the same charge sign. This effect is noticeable in TWTs, since it reduces the electron bunching and requires slightly longer slow-wave structures. We also remark that in real TWTs, emitted electrons are not forming a perfect thin and monokinetic beam, as well as the phase velocity is not constant and losses occur.

\section{FURTHER READING}

- Invention of TWTs Wathen 1954, Kompfner 1964, Kompfner 1976, Copeland 2015b.

- Technical basis about TWTs [Pierce 1950, Gilmour 1994, Faillon 2008].

- About space TWTs Kornfeld 2001.

- History of the space conquest Logsdon 1995, Butrica 1997].

- History of telecommunication Bray 1995, Gavaghan 1998.

\section{ACKNOWLEDGEMENTS}

It is a pleasure for the authors to gratefully acknowledge Olivier Agullo, Dominique Escande and Patricia Radelet-de Grave for their critical reading of the manuscript, and Guillaume Fuhr and Magali Muraglia for their stimulating comments.

[American Radio History] American Radio History website, http://www.americanradiohistory.com.

[Angel 1952] Angel Y. et Riche P. Avril-Mai 1952. "La liaison de télévision Paris-Lille", Onde Élec., 32(301302): 152-157.

[Antoni 1998] Antoni M., Elskens Y. and Escande D. F. 1998. "Explicit reduction of $N$-body dynamics to self-consistent particle-wave interaction", Phys. Plasmas, 5: 841-852, doi: 10.1063/1.872651.

[Arnold 1923] Arnold H. D. and Espenschied L. October 1923. "Transatlantic radio telephony", Bell Labs Tech. J., 2(4): 116-144, doi: 10.1002/j.1538-7305.1923.tb01295.x

[Armstrong 2015] Armstrong C. M. 2015. "The Quest for the Ultimate Vacuum Tube", IEEE Spectrum, 52(12): 28-51, doi: 10.1109/MSPEC.2015.7335797.

[Atten 1996] Atten M. 1996. Histoire, recherche télécommunications; Des recherches au CNET. 1940-1965 (Hors Série n¹4, Réseaux, CNET). 
[Baldwin 1968] Baldwin L. G. 1968. S-band power amplifier - Improvement program Final report (NASACR-101964) ntrs: 19690031483.

[Barsotti 2018] Barsotti T., Gastaud J., Pontic J. and Barentin M. 2018. "40W Q Wideband Space TWT", accepted for the $19^{\text {th }}$ IEEE International Vacuum Electronics Conference 2018 Monterey.

[Barton 1946] Barton M. A. August 1946. "Traveling Wave Tubes", Radio, 30(8): 11-13, 30-32.

[Bénisti 2016] Bénisti D. 2016. "Envelope equation for the linear and nonlinear propagation of an electron plasma wave, including the effects of Landau damping, trapping, plasma inhomogeneity, and the change in the state of wave", Phys. Plasmas, 23(10): 102105(23pp), doi: 10.1063/1.4963854 (err 24 019901).

[Bernier 1947] Bernier J. Janvier 1947. "Essai de théorie du tube électronique à propagation d'ondes", Ann. Radioélec., 2(7): 87-101.

[Bernier 1947] Bernier J. Juin 1947. "Essai de théorie du tube électronique à propagation d'ondes", Onde Élec., 27(243): 231-243.

[Blanc-Lapierre 1946] Blanc-Lapierre A. et Lapostolle P. Décembre 1946. "Contribution à l'étude des amplificateurs à ondes progressives", Ann. Télécommun., 1(12): 283-302, doi: 10.1007/BF03000767.

[Blanc-Lapierre 1947] Blanc-Lapierre A., Lapostolle P., Voge J. P. et Wallanschek R. Mai 1947. "Sur la théorie des amplificateurs à ondes progressives", Onde Élec., 27(242): 194-202.

[Blanchard 1938] Blanchard J. 1938. "Hertz, the discoverer of electric waves" Proc. IRE, 26(5): 505-515, doi: $10.1109 /$ JRPROC.1938.228325.

[Bodmer 1963] Bodmer M. G., Laico J. P., Olsen E. G. and Ross A. T. 1963. "The satellite traveling-wave tube", Bell Labs Tech. J., 42(4): 1703-1748, doi: 10.1002/j.1538-7305.1963.tb04048.x.

[Bonifacio 1987] Bonifacio R., Casagrande F. and Pellegrini C. 1987. "Hamiltonian model of a free electron laser", Opt. Commun, 61(1): 55-60, doi: 10.1016/0030-4018(87)90124-6.

[Bonifacio 1988] Bonifacio R., Casagrande F., Ferrario M., Pierini P. and Piovella N. 1988. "Hamiltonian model and scaling laws for free-electron-laser amplifiers with tapered wiggler", Opt. Commun, 66(2-3): 133-139, doi: 10.1016/0030-4018(88)90048-X

[Bonifacio 1990] Bonifacio R., Casagrande F., Cerchioni G., De Salvo Souza L., Pierini P. and Piovella N. 1990. "Physics of the high-gain FEL and superradiance", Riv. Nuovo Cim., 13(9): 1-69, doi: 10.1007/BF02770850.

[Booker 1950] Booker H. G. and Gordon W. E. 1950. "A Theory of Radio Scattering in the Troposphere" Proc. IRE, 38(4): 401-412, doi: 10.1109/JRPROC.1950.231435.

[Bray 1995] Bray J. 1995. The Communications Miracle (Springer, New York).

[Bretting 1969] Bretting J. and Klein W. 1969. "Traveling-wave tube for the communication satellite Symphonie", J. Spacecr. Rockets, 6(3): 285-288, doi: 10.2514/3.29586.

[Butrica 1997] Butrica A. J. (Editor) 1997. Beyond the Ionosphere: Fifty Years of Satellite Communication (The NASA History Series, SP-4217) ntrs: 19970026049. 
[Cabessa 1952] Cabessa R. Avril-Mai 1952. "L'apport des liaisons par faisceaux hertziens dans le domaine des télécommunications", Onde Élec., 32(301-302): 131-151.

[Chodorow 1961] Chodorow M. and T. Wessel-Berg T. 1961 "A high-efficiency klystron with distributed interaction", IRE Trans. Electron Devices, 8(1): 44-55, doi: 10.1109/T-ED.1961.14708.

[CIA 1953] CIA. November 18, 1953. Soviet Research on Traveling Wave Tube (CIA report) foia: CIARDP80-00809A000700150068-9.

[Clarke 1945a] Clarke A. C. February 1945. "Peacetime uses for V2: V2 for Ionosphere Research?", Wireless World, $\mathbf{5 1}(2): 58$.

[Clarke 1945b] Clarke A. C. May 1945. "The Space-Station: Its Radio Applications", report to the members of the British Interplanetary Society.

[Clarke 1945c] Clarke A. C. October 1945. "Extra-Terrestrial Relays: Can Rocket Stations Give World-Wide Radio Coverage?", Wireless World, 51(10): 305-308.

[Clarke 1952] Clarke A. C. 1952. The Exploration of Space (Harper \& Row, New York).

[Clarke 1968] Clarke A. C. 1968. 2001: a Space Odyssey (Hutchinson, London).

[Clarke 1973] Clarke A. C. 1973. Profiles of the future (Harper \& Row, New York) revised edition.

[Clavier 1941] Clavier A. G. and Rostas E. 1941. Electron tube and circuits employing it, U.S. Patent 2,232,050, filed May 27, 1938, issued February 18, 1941.

[Clavier 1942] Clavier A. G. and Rostas E. 1942. Electron tube and circuits employing it, U.S. Patent 2,232,756, filed June 09, 1939, issued July 14, 1942.

[Clayton 1951] Clayton R. J., Espley D. C., Griffith G. W. S. and Pinkham J. M. C. 1951. "The LondonBirmingham television radio-relay link", J. Inst. Electr. Eng., 1951(7): 222-226, doi: 10.1049/jiee2.1951 .0099

[Coaker 2008] Coaker B. and Challis T. October 2008. "Travelling Wave Tubes: Modern Devices and Contemporary Applications", Microwave Journal, (10): 32-46.

[Coe 1961] Coe D. 1961. Marconi; Pioneer of Radio (Julian Messner, Inc., New York).

[Collier 1963] Collier R. J., Helm G. D., Laico J. P. and Striny K. M. 1963. "The ground station high-power traveling-wave tube", Bell Labs Tech. J., 42(4): 1829-1861, doi: 10.1002/j.1538-7305.1963.tb04052.x.

[Copeland 2015a] Copeland J. and Haeff A. A. March 2015. "Andrew V. Haeff: Enigma of the Tube Era and Forgotten Computing Pioneer", IEEE Ann. Hist. Comput., 37: 67-74, doi: 10.1109/MAHC.2015.2.

[Copeland 2015b] Copeland J. and Haeff A. A. September 2015. "The True History of the Traveling Wave Tube", IEEE Spectrum, 52(9): 38-43, doi: 10.1109/MSPEC.2015.7226611.

[Copeland 2017] Copeland J., Haeff A. A., Gough P., and Wright C. 2017. "Screen History: The Haeff Memory and Graphics Tube", IEEE Ann. Hist. Comput., 39: 9-28, doi: 10.1109/MAHC.2016.1.

[Corliss 1972] Corliss W. R. 1972. The interplanetary Pioneers. Volume 2: System design and development (NASA-SP-279-VOL-2) ntrs: 19730009155.

[Crawford 1963] Crawford A. B., Cutler C. C., Kompfner R. and Tillotson T. C. 1963. "The research background of the Telstar experiment", Bell Labs Tech. J., 42(4): 747-751, doi: 10.1002/j.1538- 


\subsection{3.tb04017.x}

[Cuccia 1981] Cuccia C. L. 1981. Television broadcast from space systems: Technology, costs (NASA-CR169247) ntrs: 19820022555.

[Cutler 1948] Cutler C. C. 1948. "Experimental Determination of Helical-Wave Properties", Proc. IRE, 36: 230-233, doi: 10.1109/JRPROC.1948.233590

[Cutler 1956] Cutler C. C. 1956. "The Nature of Power Saturation in Traveling Wave Tubes", Bell Labs Tech. J., 35(4): 841-876, doi: 10.1002/j.1538-7305.1956.tb03805.x.

[Davies 1988] Davies M. E. and Harris W. R. 1988. RAND's Role in the Evolution of Balloon and Satellite Observation Systems and Related U.S. Space Technology (Defense Technical Information Center) dtic: ADA216963.

[Dawson 1954] Dawson G., Hall L. L., Hodgson K. G., Meers R. A. and Merriman J. H. H. "The ManchesterKirk o'Shotts television radio-relay system", Proc. IEE - Part I: General, 101(169): 93-109, doi: $10.1049 / \mathrm{pi}-1.1954 .0033$

[DoD 1997] U.S. Department of Defense. 1997. Industrial Assessment of the Microwave Power Tube Industry (Industrial Capabilities and Assessments, Pentagon, Washington, DC,) dtic: ADA323772.

[Dimonte 1977] Dimonte G. 1977. Destruction of trapped particle oscillations, Ph.D. thesis (Univ. California at San Diego, La Jolla, California).

[Doveil 2005] Doveil F., Escande D. F. and Macor A. 2005. "Experimental observation of nonlinear synchronization due to a single wave", Phys. Rev. Lett., 94: 085003(4pp), doi: 10.1103/physrevlett.94.085003.

[Doveil 2007] Doveil F., Macor A. and Aïssi A. 2007. "Observation of Hamiltonian chaos and its control in wave particle interaction", Plasma Phys. Control. Fusion, 49: 125-135, doi: 10.1088/0741$3335 / 49 / 12 \mathrm{~B} / \mathrm{S} 12$.

[Dunlap 1944] Dunlap O. E., Jr. 1944. Radio's 100 men of science (Harper \& Brothers, New York).

[Dürr 2015] Dürr W., Dürr C., Ehret P. and Bosch E. 2015. "Thales 150 W C-Band radiation cooled Travelling Wave Tube", 15th IEEE International Vacuum Electronics Conference 2015 Beijing,doi: 10.1109/IVEC.2015.7223814.

[Durkee 1947] Durkee A. L. December 1947. "A Microwave relay system between New York and Boston", Bell Labs Record, 25(12): 207-210.

[Eiffel 1900] Eiffel G. 1900. Travaux scientifiques exécutés à la tour de 300 mètres: De 1889 à 1900 (L. Maretheux, Paris).

[Elskens 2003] Elskens Y. and Escande D. F. 2003. Microscopic dynamics of plasmas and chaos (IoP publishing, Bristol).

[Elskens 2014] Elskens Y., Escande D. F. and Doveil F. 2014. "Vlasov equation and $N$-body dynamics How central is particle dynamics to our understanding of plasmas?", Eur. Phys. J. D, 68: 218(7pp), doi: $10.1140 /$ epjd/e2014-50164-9.

[ESA website] ESA website, url: http://www.esa.int. 
[Escande 2010] Escande D. F. 2010. "Wave-particle interaction in plasmas : A qualitative approach", pp. 469-506 in Dauxois T. (Editor), Ruffo S. (Editor) and Cugliandolo L. F. (Editor), Long-range interacting systems (Oxford University press, Oxford).

[Escande 2017] Escande D. F. 2017. "From thermonuclear fusion to Hamiltonian chaos", Eur. Phys. J. H, doi: $10.1140 /$ epjh/e2016-70063-5.

[Faillon 2008] Faillon G., Kornfeld G., Bosch E. and Thumm M. K. 2008. "Microwave Tubes", pp. 1-82 in Eichmeier J. A. (Editor) and Thumm M. K. (Editor) Vacuum Electronics (Springer, Berlin).

[Faulkner 1952] Faulkner H. 1952. "Permanent point-to-point links for relaying television", Proc. IEE - Part IIIA: Television, 99(18): 313-322, doi: 10.1049/pi-3a.1952.0039.

[Feldman 1965] Feldman N. E. December 1965. "Communication Satellite Output Devices, Part 2", Microwave Journal, p 87-97.

[Ferrié 1911] Ferrié G. A. 1911. "Sur quelques nouvelles applications de la télégraphie sans fil", J. Phys. Théor. Appl., 1: 178-189, doi: 10.1051/jphystap:0191100103017801.

[Field 1951] Field L. M. 1951. High-frequency amplifying device, U.S. Patent 2,575,383, filed October 22, 1946, issued November 20, 1951.

[Filep 1983] Filep R. T., Schnapf A. and Fordyce S. W. 1983. Study to forecast and determine characteristics of world satellite communications market (NASA-CR-168270) ntrs: 19840008358.

[Firpo 2001] Firpo M-C, Doveil F., Elskens Y., Bertrand P., Poleni M. and Guyomarc'h D. 2001. "Long-time discrete particle effects versus kinetic theory in the self-consistent single-wave model", Phys. Rev. E, 64: 026407(10pp), doi: 10.1103/PhysRevE.64.026407

[Fleming 1905] Fleming J. A. 1905. Instrument for converting alternating electric currents into continuous currents, U.S. Patent 803,684, filed April 19, 1905, issued November 7, 1905.

[Flint 1977] Flint P. B. December 9, 1977. "Dr. Rudolf Kompfner Dies at 68; Developer of UHF Amplification", The New York Times.

[Forest 1908] de Forest L. 1908. Space telegraphy, U.S. Patent 879,532, filed January 29, 1907, issued February $18,1908$.

[Forestier 1951] Forestier P. Octobre 1951. "Le nouveau faisceau hertzien P.T.T. Paris-Lille, à ondes centimétriques" TSF pour tous, 276: 314-316.

[Gastaud 2014] Gastaud J., Gérard E., Laurent A. and Stalzer H. 2014. "170W Ka-Band space TWT", $14^{\text {th }}$ IEEE International Vacuum Electronics Conference 2014 Monterey, doi: 10.1109/IVEC.2014.6857480

[Gavaghan 1998] Gavaghan H. 1998. Something New Under the Sun Satellites and the Beginning of the Space Age (Springer, New York).

[Gernsback 1927] Gernsback H. February 1927. "Can We Radio the Planets?", Radio News, 8(8): 946-947, 1045.

[Gertner 2012] Gertner J. 2012. The Idea Factory: Bell Labs and the Great Age of American Innovation (Penguin, London). 
[Gilmour 1994] Gilmour A. S. Jr. 1994. Principles of Traveling Wave Tubes (Artech House radar library, Boston).

[Gilmour 2011] Gilmour A. S. Jr. 2011. Klystrons, Traveling Wave Tubes, Magnetrons, Cross-Field Amplifiers, and Gyrotrons (Artech House radar library, Boston).

[Goldsmith 1946] Goldsmith A. N. (Editor), Van Dyck A. F. (Editor), Burnap R. S. (Editor), Dickey E. T. (Editor) and Baker G. M. K. (Editor) 1946. Television, Volume III (1938-1941) (RCA laboratories division, Princeton, New Jersey).

[Gootée 1946] Gootée T. April 1946. "Radar reaches the Moon", Radio News, 35(4): 25-27.

[Grant 1996] Grant T. 1996. International Directory of Company Histories, Volume 15 (St. James Press).

[Grieg 1948] Grieg D. D., Metzger S. and Waer R. 1948. "Considerations of Moon-Relay Communication", Proc. IRE, 36(5): 652-663, doi: 10.1109/JRPROC.1948.226208.

[Guénard 1952] Guénard P., Doehler O., Epsztein B. et Warnecke R. 1952. "Nouveaux tubes oscillateurs à large bande d'accord", Comptes Rendus Acad. Sci, 235: 236-238.

[Gutton 1952] Gutton H., Fagot J. et Hugon J. Avril-Mai 1952. "les équipements du faisceau hertzien Paris-Lille", Onde Élec., 32(301-302): 174-180.

[Guyomarc'h 1996] Guyomarc'h D. 1996. Un tube à onde progressive pour l'étude de la turbulence plasma, Thèse de Doctorat (Univ. Provence, Aix-Marseille I).

[Haeff 1936] Haeff A. V. 1936. Device for and method of controlling high frequency currents, U.S. Patent 2,064,469, filed October 23, 1933, issued December 15, 1936.

[Haeff 1939] Haeff A. V. February 1939. "An Ultra-High-Frequency Power Amplifier of Novel Design", Electronics, 12(2): 30-32.

[Haeff 1941a] Haeff A. V. 1941. Device for and method of controlling high frequency currents, U.S. Patent 2,233,126, priority date October 23, 1933, filed May 14, 1936, issued February 25, 1941.

[Haeff 1941b] Haeff A. V. 1941. Electron discharge device, U.S. Patent 2,237,878, filed February 2, 1939, issued April 8, 1941.

[Halsey 1952] Halsey R. J. and Williams H. 1952. "The Birmingham-Manchester-Holme Moss televisioncable system", Proc. IEE - Part IIIA: Television, 99(18): 398-410, doi: 10.1049/pi-3a.1952.0050.

[Heaviside 1902] Heaviside O. December 1902, Encyclopedia Britannica, 10 ${ }^{\text {th }}$ edition, vol. 33, p. 215.

[Hertz 1888] Hertz H. R. 1888. "Ueber die Ausbreitungsgeschwindigkeit der electrodynamischen Wirkungen", Wied. Ann., 34: 551-569, doi: 10.1002/andp.18882700708.

[Hertz 1889] Hertz H. R. 1889. "Die Kräfte electrischer Schwingungen, behandelt nach der Maxwell'schen Theorie", Wied. Ann., 36: 1-22, doi: 10.1002/andp.18882720102.

[Hertz 1893] Hertz H. R., English translation by Jones D. E. 1893. Electrical Waves (Dover Publication Inc., New York).

[Highstrete 1962] Highstrete B. A. and Grabowski K. P. 1962. 1962 International Electron Devices Meeting, doi: $10.1109 /$ IEDM.1962.187332. 
[Hulburt 1929] Hulburt E. O. 1929. "Ionization in the Atmosphere of Mars", Proc. IRE, 19(9): 1523-1527, doi: $10.1109 /$ JRPROC.1929.221855.

[Hughes heritage website] Hughes heritage website, url: http://www.hughesscgheritage.com

[IEEE 2003] IEEE. 2003. 521-2002 - IEEE Standard Letter Designations for Radar-Frequency Bands, doi: 10.1109/IEEESTD.2003.94224

[Jarrett 1964] Jarrett J. H. March 1964. "Traveling Wave Tubes", Electronics World, 71(3): 25-28.

[Jonas 2008] Jonas G. March 19, 2008. "Arthur C. Clarke, Author Who Saw Science Fiction Become Real, Dies at 90", The New York Times.

[Josifovska 2013] Josifovska S. (Editor) April 2013. "Centenary Issue", Electronics World, 119.

[Keith 1950] Keith L. J. (Editor) and Brogue A. (Editor) 1950. Father of Radio; the autobiography of Lee de Forest (Wilcox \& Follett Co., Chicago).

[Kennedy 1946] Kennedy T. R. Jr. July 06, 1946. "New tube expands radio possibilities", The New York Times.

[Kennelly 1902] Kennelly A. E. March 1902. "On the elevation of the Electrically-Conducting Strata of the Earth's Atmosphere", Electrical World and Engineer, 39(11): 473.

[Kinzer 1961] Kinzer J. P. and Laidig J. F. 1956. "Engineering aspects of the TH microwave radio relay system", Bell Labs Tech. J., 40(6): 1459-1494, doi: 10.1002/j.1538-7305.1961.tb01648.x.

[Kohlhaas 1931] Kohlhaas H. T. June-July 1931. "7 Inch Waves Span 21 Miles", Short wave craft, 2(1): 10-11, 65-66.

[Kompfner 1946] Kompfner R. 1946. "The Traveling Wave Valve", Wireless World, 52(11): 369-372.

[Kompfner 1947] Kompfner R. 1947. "The traveling wave tube as an amplifier at microwaves", Proc. IRE, 35(2): 124-127, doi: 10.1109/JRPROC.1947.231238

[Kompfner 1947b] Kompfner R. 1947. "The Travelling-Wave Tube, Centimetre-Wave Amplifier", Wireless Engineer, 53(9): 255-266.

[Kompfner 1952] Kompfner R. 1952. "Travelling-wave tubes", Rep. Prog. Phys., 15: 275-327, doi: 10.1088/0034-4885/15/1/309.

[Kompfner 1964] Kompfner R. 1964. The invention of traveling wave tubes (San Francisco Press, San Francisco).

[Kompfner 1976] Kompfner R. 1976. "The invention of traveling wave tubes", IEEE Trans. Elec. Devices, 23: 730-738, doi: 10.1109/T-ED.1976.18477.

[Kornfeld 2001] Kornfeld G. and Bosch E. 2001. "From History to Future of Satellite TWT Amplifiers", Frequenz, 55: 258-262, doi: 10.1515/FREQ.2001.55.9-10.258

[Kosmahl 1982] Kosmahl H. 1982. Space tubes: A major challenge (1982 International Electron Devices Meeting IEEE) ntrs: 19830003177.

[Kosmahl 1983] Kosmahl H. 1983. "Space power tubes - very much alive" Cleveland Electronic Conference (CECON '83) IEEE, ntrs: 19830020024. 
[Lindenblad 1939] Lindenblad N. E. April 1939. "Television transmitting antenna for Empire State Building”. RCA Review, 111(4): 387-408.

[Lindenblad 1942] Lindenblad N. E. 1942. Electron discharge device system, U.S. Patent 2,300,052, filed May 4, 1940, issued October 27, 1942.

[Lindenblad 1951] Lindenblad N. E. 1951. High-frequency electron discharge device of the traveling wave type, U.S. Patent 2,578,434, filed June 25, 1947, issued December 11, 1951.

[Lindenblad 1954] Lindenblad N. E. 1954. High-frequency electron discharge device, U.S. Patent 2,679,019, filed December 2, 1947, issued May 18, 1954.

[Llewellyn 1937] Llewellyn F. B. 1937. Space discharge apparatus, U.S. Patent 2,096,460, filed January 23, 1936, issued October 19, 1937.

[Llewellyn 1945] Llewellyn F. B. 1945. Electron discharge device, U.S. Patent 2,367,295, filed May 17, 1940, issued January 16, 1945.

[Logsdon 1995] Logsdon J. M. (Editor) 1995 to 2008. Exploring the Unknown, volumes I to VII (The NASA History Series).

[Loshakov 1949] Loshakov L. N. May 1949. "On the propagation of waves along a coaxial spiral line in the presence of an electron beam", Zh. Tech. Fiz., 19: 578-595.

[Lowell 1896] Lowell P. 1896. Mars (Houghton, Mifflin and Co, Boston).

[Lowell 1906] Lowell P. 1906. Mars and its canals (The Macmillan company, New York).

[Martin 1952] Martin A. V. J. 1952. "International TV is here", Radio News, 48(6): 31-33,118-119.

[Marzin 1951] Marzin P. 1951. "Les câbles hertziens", Ann. Télécommun., 6(12): 363-380, doi: 10.1007/BF03013875.

[Maxwell 1865] Maxwell J. C. 1865. "A Dynamical Theory of the Electromagnetic Field", Philos. Trans. Royal Soc., 155: 459-512.

[McDowell 1960] McDowell H. L. June 1960. "The Traveling-Wave Tube Goes to Work", Bell Labs Record, 38(6): 207-210.

[McKenzie 1946] McKenzie A. A. (Editor) September 1946. "New Products: Traveling Wave Tube", Electronics, 29: 206.

[Mehrholz 2002] Mehrholz D., Leushacke L., Flury W., Jehn R., Klinkrad H., and Landgraf M. February 2002. "Detecting, Tracking and Imaging Space Debris", ESA bulletin, 109: 128-134.

[Mendel 1973] Mendel J. T. 1973. "Helix and coupled-cavity traveling-wave tubes", Proc. IEEE, 61(3): 280-298, doi: 10.1109/PROC.1973.9032.

[Minenna 2016] Minenna D. F. G. 2016. Description hamiltonienne de l'interaction ondes-électrons dans un guide d'onde périodique, M. Sc. thesis (Aix-Marseille Univ., Marseille).

[Minenna 2017] Minenna D. F. G., Elskens Y. and André F. 2017. "Electron-wave momentum exchange and time domain simulations applied to traveling wave tubes", $18^{\text {th }}$ IEEE International Vacuum Electronics Conference 2017 London, doi: 10.1109/IVEC.2017.8289689.

[Miquel 1973] Miquel P. 1973. Histoire de la radio et de la télévision (Édition Richelieu, Paris). 
[Mofenson 1946] Mofenson J. April 1946. "Radar echoes from the Moon", Electronics, 19(4): 92-98.

[Morton 1949] Morton J. A. May 1949. "A microwave triode for radio relay", Bell Labs Record, 27(5): 166-170.

[NASA 1963a] NASA. 1963. Telstar I, volume 3 (NASA Technical Report SP-32) ntrs:19640001170.

[NASA 1963b] NASA. 1963. Advanced Syncom, volume 1 (NASA-CR-74485) ntrs: 19660014301.

[NASA 1963c] NASA. 1963. Advanced Syncom, volume 4 (NASA-CR-74580) ntrs: 19660015211.

[NASA 1965] NASA. 1965. Relay I program, Final report (NASA-SP-76) ntrs: 19660000937.

[NASA 1977] NASA. 1977. Two Voyagers set for launch (NASA-NEWS-RELEASE-77-136, P77-10165) ntrs: 19770079866.

[NASA website] NASA website, url: https://www.nasa.gov//

[Nomura 1954] Nomura T., Suzuki N., Mita S. and Sawazaki N. June 1954. "Microwave Relay for Japanese Television", Electronics, 27(6): 152-156.

[Obituary 1978] Obituary. February 20, 1978. "Nils E. Lindenblad, at 82, a pioneer in radio and TV", The New York Times.

[Obituary 2014] Obituary. February 14, 2014. "John Thomas Mendel", Los Angeles Times.

[Ogata 1985] Ogata M., Mizusawa H. and Irie K. 1985. Discussion on the progress and future of satellite communication (Japan) (NASA-TM-77672) ntrs: 19860000911.

[Pchelnikov 2003] Pchelnikov Y. N. 2003. "Old Know-How in Helix TWT Development in the USSR", High Energy Density and High Power RF: $6^{\text {th }}$ Workshop (American Institute of Physics).

[Pellegrini 2012] Pellegrini C. 2012. "The history of X-ray free-electron lasers", Eur. Phys. J. H 37: 659-708, doi: $10.1140 /$ epjh/e2012-20064-5

[Percival 1937] Percival W. S. 1937. Improvements in and relating to thermionic valve circuits, British Patent Specification No. 460 562, filed July 24, 1935, accepted January 25, 1937.

[Philips 2014] Philips Natuurkundig Laboratorium history website, url: http://extra.research. philips.com

[Pierce 1946] Pierce J. R. December 1946. "The beam traveling-wave tube", Bell Labs Record, 24(12): 439-442.

[Pierce 1947a] Pierce J. R. and Field L. M. 1947. "Traveling-wave tubes", Proc. IRE, 35(2): 108-111, doi: 10.1109/JRPROC.1947.226216.

[Pierce 1947b] Pierce J. R. 1947. "Theory of the beam-type as amplifier at microwaves", Proc. IRE, 35(2): 111-124, doi: 10.1109/JRPROC.1947.226217

[Pierce 1950] Pierce J. R. 1950. Traveling wave tubes (Van Nostrand, New York).

[Pierce 1952a] Pierce J. R. 1952. Traveling wave tube, U.S. Patent 2,602,148, filed October 22, 1946, issued July 1, 1952.

[Pierce 1952b] Pierce J. R., under the pseudonym J. J. Coupling. March 1952. "Don’t Write: Telegraph!", Astounding Science Fiction, 49: 82-96. 
[Pierce 1955] Pierce J. R. 1955. "Orbital Radio Relays", Jet Propulsion, 25(4): 153-157, doi: $10.2514 / 8.6641$.

[Pierce 1959a] Pierce J. R. September 1959. "Exotic Radio Communications", Bell Labs Records, 37(9): 323-329.

[Pierce 1959b] Pierce J. R. and Kompfner R. 1959. "Transoceanic Communication by Means of Satellites", Proc. IRE, 47(3): 372-380, doi: 10.1109/JRPROC.1959.287173

[Pierce 1962] Pierce J. R. 1962. "History of the Microwave-Tube Art", Proc. IRE, 50(5): 978-984, doi: 10.1109/JRPROC.1962.288385.

[Pierce 1968] Pierce J. R. 1968. The Beginnings of Satellite Communications (San Francisco Press, San Francisco).

[Pocklington 1897] Pocklington H. C. 1897. "Electrical oscillations in wires", Proc. Camb. Phil. Soc., 9: 324.

[Posthumus 1935] Posthumus K. March 1935. "Oscillations in split anode magnetron", Wireless Engineer, 12(138): 126-132.

[Potter 1938] Potter R. K. 1938. Wave amplifier, U.S. Patent 2,122,538, filed January 22, 1935, issued July 5, 1938.

[Project RAND 1946] Project RAND. May 1946. Preliminary Design of an Experimental World-Circling Spaceship (Report No. SM-11827, Douglas Aircraft Company Inc., Santa Monica, CA).

[Rayleigh 1897] Rayleigh (Lord) 1897. "On the passage of electric waves through tubes, or the vibrations of dielectric cylinders", Phil. Mag., 43(261): 125-132, doi: 10.1080/14786449708620969.

[Roberts 1967] Roberts L. A. 1967. The efficiency improvement program for the WJ-274 traveling wave tube (NASA-CR-66522) ntrs: 19680004733.

[Roberts 1939] Roberts W. V. B. 1939. Electron discharge device circuit, U.S. Patent 2,168,782, filed October 7, 1935, issued August 8, 1939.

[Rockett 1946] Rockett F. (Editor) November 1946. "Wideband Microwave Amplifier Tube", Electronics, 29: $90-92$.

[Roetken 1951] Roetken A. A., Smith K. D. and Friis R. W. 1951. "The TD-2 microwave radio relay system" Bell Labs Tech. J., 30(4): 1041-1077, doi: 10.1002/j.1538-7305.1951.tb03696.x.

[Rogers 1949] Rogers D. C. June 1949. "Travelling-Wave Amplifier for 6 to 8 Centimetres", Electrical Communication, 26(2): 144-152.

[Rogers 1953] Rogers D. C. 1953. "The Travelling-Wave Tube as Output Amplifier in Centimetre-Wave Radio Links", Proc. IEE-Part III: Radio and Communication Engineering, 100(65): 151-156, doi: 10.1049/pi-3.1953.0034.

[Rosenberg 1972] Rosenberg H. R. (Editor) 1972. Apollo experience report: S-band system signal design and analysis (NASA-TN-D-6723) ntrs: 19720012253.

[Roubine 1947] Roubine E. Mai 1947 "Sur le circuit à hélice utilisé dans le tube à ondes progressives", Onde Élec., 27(242): 203-205. 
[Rowe 1965] Rowe J. E. 1965. Nonlinear Electron-Wave Interaction Phenomena (Academic Press Inc., New York).

[Sauseng 1968] Sauseng O. G., Basiulis A. and Tammaru I. 1968. Analytical study program to develop the theoretical design of traveling-wave tubes Final report (NASA-CR-72450) ntrs: 19690009543.

[Sawazaki 1956] Sawazaki N. and Honma T. 1956. "New Microwave Repeater System Using Traveling-Wave Tubes", Proc. IRE, 44(1): 19-24, doi: 10.1109/JRPROC.1956.274845.

[Saxon 2002] Saxon W. April 5, 2002. "John Robinson Pierce, 92, A Father of the Transistor", The New York Times.

[Schafer 1961] Schafer J. P. and Brandt R. H. October 1961. Project Echo - 960-megacycle, 10-kilowatt transmitter (NASA-TN-D-1129) ntrs: 19980227850.

[Schmid 1967] Schmid P. E. 1967. The feasibility of a direct relay of Apollo spacecraft data via a communication satellite (NASA-TN-D-4048) ntrs: 19670025652.

[Schwartz 2008] Schwartz M. and Hayes J. 2008. "A history of transatlantic cables", IEEE Commun. Mag., 49(9): 42-48, doi: 10.1109/MCOM.2008.4623705.

[Sengupta 2003] Sengupta D. L. and Sarkar T. K. 2003. "Maxwell, Hertz, the Maxwellians, and the early history of electromagnetic waves", IEEE Antennas Propag. Mag., 45(2): 13-19, doi: 10.1109/MAP.2003.1203114

[Shulman 1947] Shulman C. and Heagy M. S. December 1947. "Small-signal analysis of traveling-wave tube", R.C.A. Rev., 8(4): 585-611.

[Siddiqi 2002] Siddiqi A. A. 2002. Deep Space Chronicle: A Chronology of Deep Space and Planetary Probes 1958-2000 (NASA/SP-2002-4524) ntrs: 20020052429.

[Siegmeth 1973] Siegmeth A. J., Purdue R. E. and Ryan R. E. 1973. Tracking and data system support for the Pioneer project. Volume 1: Pioneer 10-prelaunch planning through second trajectory correction, 4 December 1969 - 1 April 1972 (NASA-CR-131373) ntrs: 19730011461.

[Smith 1953] Smith H. F. (Editor) June 1953. "International Televition: Radio and Cable 2,000-mile Network for the Coronation Transmissions", Wireless World, 59(6): 274-275.

[STC 1939] Standard Telephones and Cables. 1939. Ultra-high Frequency Electron Discharge Systems for Dielectric Guide Transmission Systems, British Patents 508,354, filed November 4, 1938, issued June 29, 1939.

[STC 1941] Standard Telephones and Cables. 1941. Circuit Employing Discharge Valves, British Patents 533,613, filed October 27, 1939, issued February 17, 1941.

[Thales] Thales internal references, private communication.

[Thayer 1949] Thayer G. N., Roetken A. A., Friis R. W. and Durkee A. L. 1947. "A Broad-Band Microwave Relay System between New York and Boston", Proc. IRE, 37(2): 183-188, doi: 10.1109/JRPROC.1949.230944.

[Thomson 1893] Thomson J. J. 1893. Recent researches in electricity and magnetism (Clarendon Press, Oxford). 
[Titchmarsh 2013] Titchmarsh A. 2013. Elizabeth: Her Life, Our Times (Ebury Publishing, London).

[Tolstoy 1985] Tolstoy A., English translation by Fetzer L. 1985. Aelita, or, the Decline of Mars (Ardis, New York).

[Tsunoda 1982] Tsunoda S. I. and Malmberg J. H. 1982. "Effect of a Static Electric Field on the Trapping of Beam Electrons in a Slow Wave Structure", Phys. Rev. Lett., 49: 546-549, doi: 10.1103/physrevlett.49.546,

[Tsunoda 1982] Tsunoda S. I. 1982. Wave enhancement due to a static electric field, Ph.D. thesis (Univ. California at San Diego, La Jolla, California).

[Tsunoda 1987] Tsunoda S. I., Doveil F. and Malmberg J. H. 1987. "Experimental test of the quasilinear theory of the interaction between a weak warm electron beam and a spectrum of waves", Phys. Rev. Lett., 58: 1112-1115, doi: 10.1103/physrevlett.58.1112

[Tucek 2016] Tucek J. C., Basten M. A., Gallagher D. A. and Kreischer K. E. 2016. "Operation of a compact $1.03 \mathrm{THz}$ power amplifier", 17th IEEE International Vacuum Electronics Conference 2016 Monterey, doi: $10.1109 /$ IVEC.2016.7561772.

[Tweether] Tweether website, url: https://tweether.eu/

[Unk. 1920] Unknown. December 1920. "The Eiffel Tower Radio Station", Radio News, 2(6); 350-352,417.

[Unk. 1951] Unknown. April 1951. "Manchester-Edinburgh Television Radio Relay System" Post Office Electrical Engineers' Journal, 44: 33-34.

[Unk. 2017] Unknown. September 5, 2017. "Le satellite Telkom 1 ne répond plus, le système bancaire touché", le Courrier International.

[Verne 1865] Verne J. 1865. De la Terre à la Lune, trajet direct en 97 heures 20 minutes.

[Voge 1946] Voge J. Décembre 1946. "Sur deux schémas d'amplificateurs électroniques pour très hautes fréquences à onde progressive", Comptes Rendus Acad. Sci, 223: 1117-1119.

[Voge 1957a] Voge J. Mars 1957. "Tubes à onde progressive", Ann. Télécommun., 12(3): 92-104, doi: $10.1007 / \mathrm{BF} 03023859$.

[Voge 1957b] Voge J. Avril 1957. "Tubes à onde progressive", Ann. Télécommun., 12(4): 105-119, doi: 10.1007/BF03013793.

[Voge 1973] Voge J. 1973. Les Tubes aux Hyperfréquences (Collection Technique et Scientifique du CNET, Éditions Eyrolles, Paris) $4^{\mathrm{e}}$ édition.

[Warnecke 1956] Warnecke R. R. Novembre 1956. "Principaux résultats acquis dans le domaine des tubes électroniques pour hyperfréquences", Congrès International Tubes Hyperfréquences, 1956, Paris, printed in Onde Élec., 36(356): 875-887.

[Wathen 1954] Wathen R. L. December 1954. "The traveling wave tube-A record of its early history", $J$. Franklin Inst., 258(6): 429-442, doi: 10.1016/0016-0032(54)90001-0.

[Wessel-Berg 1957] Wessel-Berg T. 1957. "A General Theory of Klystrons with Arbitrary, Extended Interaction Fields", Report No. 376 (Microwave Lab., Stanford Univ., Stanford). 
[White 1952] White L. 1952. Final Report, Project Hermes V-2 Missile Program (Report No. R52A0510, General Electric Company, Schenectady, N.Y.).

[Whitmore 1946] Whitmore W. (Editor) October 1946. "New Traveling Wave Tube", Western Electric Oscillator, 5: 35 .

[Wichter 2017] Wichter Z. February 2, 2017. "Harold Rosen, Who Ushered in the Era of Communication Satellites, Dies at 90", The New York Times.

[Wildhack 1946] Wildhack W. A. (Editor) 1946. "New Instruments: Beam Traveling-Wave Amplifier Tube", Rev. Sci. Instrum, 17(12): 559-560, doi: 10.1063/1.1770432.

[Young 1965] Young L. H. (Editor) December 13, 1965. "Special Report : Japanese technology", Electronics, 38(25): 77-112.

[Zaleski 2011] Zaleski R., Mirczak W., Staich S., Caverly R., Smith E., Teti N., Vaught W. L. and Olney D. 2011. "Innovative Approach Enabled the Retirement of TDRS-1 Compliant with NASA Orbital Debris Requirements", 2011 IEEE Aerospace Conference.

[Zworykin 1937] Zworykin V. K. 1937. Direction indicator, U.S. Patent 2,103,507, filed March 31, 1936, issued December 28, 1937. 